\title{
Cutaneous Malassezia: Commensal, Pathogen, or Protector?
}

\author{
Shree Harsha Vijaya Chandra ${ }^{1+}$, Ramasamy Srinivas ${ }^{1+}$, Thomas L. Dawson $\mathrm{Jr}^{1,2^{*}}$ \\ and John E. Common ${ }^{1 *}$ \\ ${ }^{1}$ Skin Research Institute of Singapore, Agency for Science, Technology and Research, Singapore, Singapore, ${ }^{2}$ Department \\ of Drug Discovery, College of Pharmacy, Medical University of South Carolina, Charleston, SC, United States
}

OPEN ACCESS

Edited by:

Guilhem Janbon,

Institut Pasteur, France

Reviewed by:

Chaoyang Xue,

Rutgers University, Newark,

United States

Vishukumar Aimanianda,

Institut Pasteur, France

*Correspondence:

John E. Common

john.common@sris.a-star.edu.sg

Thomas L. Dawson Jr.

thomas_dawson@sris.a-star.edu.sg

${ }^{\dagger}$ These authors have contributed equally to this work

Specialty section: This article was submitted to

Fungal Pathogenesis,

a section of the journal

Frontiers in Cellular

and Infection Microbiology

Received: 06 October 2020

Accepted: 04 December 2020

Published: 26 January 2021

Citation:

Vijaya Chandra SH, Srinivas $R$, Dawson TL Jr and Common JE (2021) Cutaneous Malassezia: Commensal,

Pathogen, or Protector? Front. Cell. Infect. Microbiol. 10:614446.

do: 10.3389/fcimb.2020.614446
The skin microbial community is a multifunctional ecosystem aiding prevention of infections from transient pathogens, maintenance of host immune homeostasis, and skin health. A better understanding of the complex milieu of microbe-microbe and hostmicrobe interactions will be required to define the ecosystem's optimal function and enable rational design of microbiome targeted interventions. Malassezia, a fungal genus currently comprising 18 species and numerous functionally distinct strains, are lipiddependent basidiomycetous yeasts and integral components of the skin microbiome. The high proportion of Malassezia in the skin microbiome makes understanding their role in healthy and diseased skin crucial to development of functional skin health knowledge and understanding of normal, healthy skin homeostasis. Over the last decade, new tools for Malassezia culture, detection, and genetic manipulation have revealed not only the ubiquity of Malassezia on skin but new pathogenic roles in seborrheic dermatitis, psoriasis, Crohn's disease, and pancreatic ductal carcinoma. Application of these tools continues to peel back the layers of Malassezia/skin interactions, including clear examples of pathogenicity, commensalism, and potential protective or beneficial activities creating mutualism. Our increased understanding of host- and microbe-specific interactions should lead to identification of key factors that maintain skin in a state of healthy mutualism or, in turn, initiate pathogenic changes. These approaches are leading toward development of new therapeutic targets and treatment options. This review discusses recent developments that have expanded our understanding of Malassezia's role in the skin microbiome, with a focus on its multiple roles in health and disease as commensal, pathogen, and protector.

Keywords: Malassezia, commensal, pathogen, mutualist, multikingdom, immunity, skin, host and disease

\section{MALASSEZIA: A MAJOR COMPONENT OF THE SKIN MICROBIOME}

Human skin serves as our protective physical barrier, but also consists of a complex microenvironmental ecosystem. The skin surface micro-environment is colonized by a wide range of microorganisms, including bacteria, archaea, viruses, and fungi, collectively referred to as the skin microbiome. While initially considered as a $2 \mathrm{~m}^{2}$ flat surface representing a smaller and less influential 
niche than gut or lung, when one considers skin's 3-dimensional topography it becomes an estimated $30 \mathrm{~m}^{2}$, similar in surface area to gut or lung. This, coupled with access to viable epidermis in deeper invaginations (such as the follicle infundibulum), the skin becomes an important and relevant microbial niche (Gallo, 2017). The complex ecosystem in any individual is governed by the skin's divergent niches, ranging from dry (heel, volar forearm) to moist (antecubital fossa, axilla) to dry and oily (face, upper back) to moist and oily (scalp), driving high microbial variability between niches. While there remains microbial variability between individuals, it is relatively low compared to that between different body site niches (Grice et al., 2009; Oh et al., 2014). Multikingdom DNA sequencing has revealed the skin microbiome has notably higher viral and fungal representation when compared to gut (Arumugam et al., 2011; Oh et al., 2014). The skin microbiome is also temporally stable over long periods regardless of the environmental perturbations experienced in daily life (Oh et al., 2016). Factors such as short term washing with common (non-antimicrobial) hygiene products does not disrupt the skin commensal microbial diversity, but can help displace opportunistic pathogenic colonizers (Two et al., 2016). The eukaryotic component of skin microbiome is dominated by Malassezia (Findley et al., 2013; Oh et al., 2014; Jo et al., 2016; Byrd et al., 2018), which are found in highest abundance on sebaceous sites including scalp, face, chest, and upper back, and in lower abundance on trunk and arms. Feet are the exception with lower Malassezia content and higher overall fungal diversity (Table 1) (Findley et al., 2013). Interestingly, the diversity of commensal skin fungi can also vary with geography and possibly ethnicity in healthy individuals (Leong et al., 2019).

Metagenomics defines the genetic information from a single microbe as one functional unit, a set of genes, and is used as such to determine the presence of individual microorganisms and predict abundance. However, the relative number of genomes provides an estimate of abundance independent of the cellular size, or interactive biomass, which differs considerably between organisms. For metagenomic ecological analyses, it is important to consider the potential biomass of each microbial community member, as biomass is how bacteria, fungi, or viruses interact with the host as a functional unit. Using conservative estimates of cell size, Malassezia have 200-500 times the cellular biomass per genome relative to Staphylococcus epidermidis. Hence it would be reasonable and likely meaningful to consider biomass availability during interaction with the host (Ramasamy et al., 2019). Doing so promotes the fungal biomass component of sebaceous skin to at least an equal footing with bacteria.

Molecular phylogenetic and genomic studies have shown Malassezia belong to Basidiomycota, Ustilagomycotina and class Malasseziomycetes. Malassezia have undergone an unfortunate and complex series of nomenclature changes which have clouded their research history. Originally discovered by Malassez and Sabaouraud in the late $19^{\text {th }}$ century, their resistance to cultivation led to the conclusion that there was one species, named Malassezia (Malassez, 1874; Sabouraud, 1897). In the 1950's there were three identified species, renamed as Pityrosporum (which is still found in some textbooks): $P$. ovale, named for their oval shape; $P$. orbiculare, for their round shape; and $P$. pachydermatis, as the species found on animal as opposed to human skin (Rhoda, 1939). Other nomenclature included $M$. furfur serovars (A, B or C) now reclassified as A-M. furfur, B-M. globosa and C-M. restricta (Cunningham et al., 1990; Ashbee et al., 1993; Batra et al., 2005). Today the Malassezia genus is diverse and comprises 18 species, with numerous functionally distinct strains (Figure 1) (Theelen et al., 2019). Malassezia have haploid genomes of 8-9 $\mathrm{Mb}$, among the smallest for free-living fungi. They have evolved genetic content enriched for genes specific to their environment, encoding lipases, phospholipases and acid sphingomyelinases for utilization of lipids, and proteases for utilization of proteins (Poh

TABLE 1 | Summary of currently described Malassezia species present in human body sites associated with health and/or disease.

\begin{tabular}{|c|c|c|c|c|c|}
\hline $\begin{array}{l}\mathbf{S} / \\
\mathbf{N}\end{array}$ & Malassezia Species & $\begin{array}{l}\text { Group } \\
\text { (Figure 1) }\end{array}$ & $\begin{array}{l}\text { Body site }^{\dagger} \\
\text { (Human) }\end{array}$ & $\begin{array}{l}\text { Health/ } \\
\text { Disease }^{\ddagger}\end{array}$ & References \\
\hline 1 & M. furfur & A & D, S, SC, Sy & $\begin{array}{l}\text { AD, D, SD, } \\
\text { PV, SI, F }\end{array}$ & $\begin{array}{l}\text { (Simmons and Gueho, 1990; Boekhout T et al., 2010; Cabanes, 2014; latta } \\
\text { et al., 2014) }\end{array}$ \\
\hline 2 & M. obtusa & A & $\mathrm{D}, \mathrm{S}$ & $A D, D, S D$ & (Boekhout T et al., 2010; Cabanes, 2014; Prohic et al., 2016) \\
\hline 3 & M. japonica & A & $D, S$ & $A D$ & (Sugita et al., 2003) \\
\hline 4 & M. yamatoensis & A & $D, S$ & $A D, S D$ & (Sugita et al., 2004; Boekhout T et al., 2010) \\
\hline 5 & M. sympodialis & B & $D, M, S$ & $\begin{array}{l}\mathrm{D}, \mathrm{SD}, \mathrm{AD} \\
\mathrm{PV}, \mathrm{F}\end{array}$ & $\begin{array}{l}\text { (Gupta et al., 2004; Boekhout T et al., 2010; Aguirre et al., 2015; Patron, } \\
\text { 2016) }\end{array}$ \\
\hline 6 & M. dermatis & $\mathrm{B}$ & $D, S$ & $\mathrm{AD}$ & $\begin{array}{l}\text { (Sugita et al., 2002; Boekhout T et al., 2010; Guého-Kellermann and Begerow, } \\
\text { 2010) }\end{array}$ \\
\hline 7 & M. restricta (all humans) & B & $\mathrm{D}, \mathrm{M}, \mathrm{S}, \mathrm{F}$ & $D, S D, A D, P$ & $\begin{array}{l}\text { (Nakabayashi et al., 2000; Batra et al., 2005; Boekhout T et al., 2010; Guého- } \\
\text { Kellermann and Begerow, 2010) }\end{array}$ \\
\hline 8 & M. globosa (all humans) & B & $D, M, S, F$ & $\begin{array}{l}D, S D, A D \\
P V, P\end{array}$ & (Gupta et al., 2004; Boekhout T et al., 2010; Cabanes, 2014) \\
\hline 9 & $\begin{array}{l}\text { M. pachydermatis (normally } \\
\text { animal, not human) }\end{array}$ & $\mathrm{B}$ & Sy & SI & (Boekhout T et al., 2010; Chow et al., 2020) \\
\hline 10 & M. arunalokei & $\mathrm{B}$ & S, ear & $\mathrm{D}, \mathrm{SD}$ & (Honnavar et al., 2016) \\
\hline 11 & M. slooffiae (rare) & $\mathrm{C}$ & $D, S$ & $\mathrm{SD}$ & (Boekhout T et al., 2010) \\
\hline
\end{tabular}

Non-human associated species: M. brasiliensis (Parrot-Group A); M. psittaci (Parrot-Group A); M. equina (Horse, Cow); M. nana (Cat, cow, Dog-Group B); M. caprae (Goat, Horse-Group B); M. vespertilionis (Bat-Group C); M. cuniculi (Rabbit-Group C).

${ }^{+}$Body Site: SC-Scalp; F-foot; Sy- systemic (blood, urine); S-sebaceous; M-moist; D-dry.

${ }^{\ddagger}$ Health/Disease: AD-Atopic dermatitis, PV-Pityriasis Versicolor; D-Dandruff; SD-seborrheic dermatitis; P-psoriasis; F-folliculitis; SI-systemic infections. 
et al., 2020). They lack a fatty acid synthase and $\delta$ - 9 desaturase, likely due to their habitation on oil rich sebaceous skin, and hence have an evolutionary inability to synthesize lipids as part of their adaptation to life on skin (Saunders et al., 2012; White et al., 2014; Wu et al., 2015). The most closely related and wellestablished fungus is the plant pathogen Ustilago maydis, which also targets their plant host for degradation, but via secretion of enzymes to break down proteins, pectin, and wax common to plant surfaces. Interestingly, while closely phylogenetically related to Ustilago, Malassezia secrete an enzyme armada much more similar to the distantly related Candida albicans, an example of niche-specific evolution (Xu et al., 2007).

The Malassezia clade can be subdivided into three major groups, as seen in Figure $\mathbf{1}$ and Table 1. Group A are represented as $M$. furfur-like, are more robust in culture, less frequent inhabitants of human skin and more often linked to skin or septic disease. Group $\mathrm{B}$ are more common on healthy human skin, with $M$. restricta and M. globosa by far the most common and found on the skin of all humans, followed by M. sympodialis, then distantly by the other Group B members. The Group B exception is M. pachydermatis, which can cause human septic infections but is only normally found on animal skin. Figure $\mathbf{1}$ also reveals pathways of chromosomal rearrangements resulting from centromere loss of function (Sankaranarayanan et al., 2020). A nine-chromosome ancestral lineage is hypothesized, which carried through to most of Group B. One centromere was lost to generate the eight-chromosome $M$. sympodialis group, and then another to generate the sevenchromosome Group C. M. pachydermatis and M. obtusa remain six-chromosome outliers. A series of horizontal gene transfers have been defined and further cloud the phylogeny (Ianiri et al., 2020). For example, another recent LSU tree, while very similar implies different grouping and relationships (Ianiri and Heitman, 2020). These findings highlight that while much has been learned about Malassezia phylogeny there is still a long way to go to understanding this unusual clade. Unfortunately, many Malassezia species do not have complete genomes, so further long read sequencing and assembly of chromosome-level genomes will be necessary to further refine Malassezia evolution. The lack of capability to cultivate many Malassezia species and strains has been an impediment to genome sequencing and characterization of gene function. Developing new culture conditions to allow cultivation of new species and continuation of the consortium/repository based exchange of genome information will advance understanding about Malassezia. The genomic relatedness of known and sequenced Malassezia spp. is useful for future species genome assembly and gene assignment, but unfortunately a large number of Malassezia genes fall into the category of unknown function and exist as families of similar gene structure. The reasons for duplication or multiplication of genes in Malassezia in the perspective of evolution could be addressed by genome evolution studies (Sankaranarayanan et al., 2020). The availability of more complete Malassezia genomes will further the understanding of unknown gene function, identify

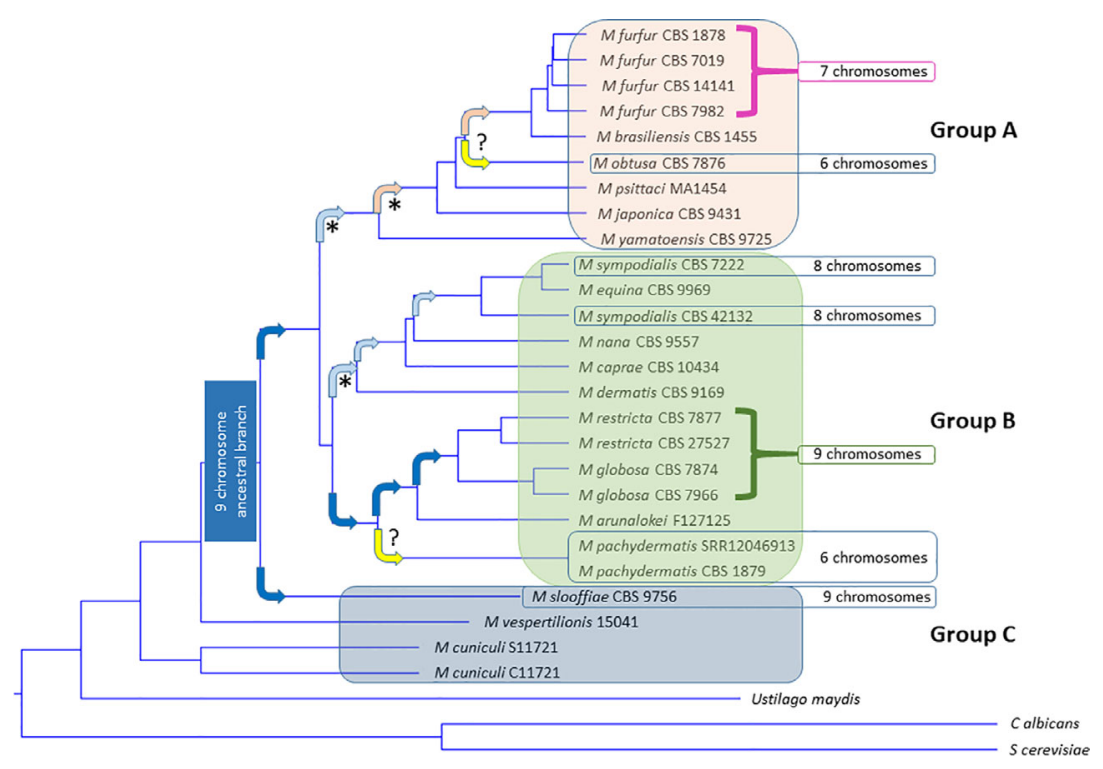

FIGURE 1 | Phylogenetic tree of all 18 currently accepted Malassezia species. Malassezia can be subdivided into subgroups A, B, and C based on Wu et al. PLoS Genetics 2015. Tree constructed from most current NCBI LSU data (Table 1) using the MAFFT method to generate multi-align sequence (MSA), UPGMA (unweighted pair group method with arithmetic mean) for clustering, phylogenetic tree viewed using Newick viewer. MAFFT v6.864 is a multiple alignment program for amino acid or nucleotide sequences (Katoh et al., 2005). (http://www.trex.uqam.ca/index.php?action=mafft and http://mafft.cbrc.jp/alignment/software/). Known species of inhabitation and activities can be found in Table 1. Arrows indicate hypothesized chromosome losses associated with development of new species (Sankaranarayanan et al., 2020). Dark blue box = nine chromosome ancestral lineage. Dark blue arrows, nine chromosome lineages. Light blue arrow predicted centromere loss to eight chromosomes. Pink arrow predicted centromere loss to seven chromosomes. Orange arrow unknown chromosome loss to six chromosomes. Yellow unknown event $)$ ? resulting in loss to six chromosomes. ( ${ }^{\star}=$ documented by centromere loss) (M. pachydermatis chromosome number postulated from complete genome assemblies, M. obtusa hypothesized based on PGFE karyotype) (Kiuchi et al., 1992; Boekhout et al., 1998; Kim et al., 2018). 
potential pathways to harness unidentified roles in host-commensal or host-pathogen interactions.

Historically, Malassezia genetic engineering has been extremely challenging. However, it has now been accomplished via agrobacterium-mediated transformation (Ianiri et al., 2016; Celis et al., 2017; Ianiri and Heitman, 2020). For example, gene deletion of a bacterially derived flavohemoglobin gene found in all Malassezia spp. detoxifies skin generated nitric oxide and is involved in Malassezia/Host interaction (Ianiri et al., 2020). Other gene deletion studies have shown that the multidrug transported PDR10 is involved in Malassezia furfur antimicrobial resistance (Ianiri et al., 2019). Finally, insertion of marker and tracking genes into Malassezia for use in in vitro, ex vivo, and in vivo models should assist in more detailed investigation of Malassezial Host interactions (Goh et al., 2020). Improved gene and genome information will assist with further identification of novel proteins that trigger skin disease, inflammation, antifungal response, immunological response of host and mechanistic functions in clinical perspective.

Microbial community and host interactions have multiple effects: broadly classified as commensal, pathogenic, or mutualistic (Schommer and Gallo, 2013). Commensalism is an active relationship between individuals of two species in which one species obtains benefits from the other without benefiting the latter. In a commensal paradigm Malassezia obtains the benefit of a food source while causing no effect to the human host. Pathogenicity is a relationship where one member is harmed, in this situation with Malassezia activity resulting in direct host damage through specific secreted virulence factors or toxins that negatively affect the host; or indirectly through induction of a damaging host response. In fungal infection, it is necessary to have a functional definition of virulence and pathogenicity, termed a "Damage Response Framework (DRF). In the DRF, a "causal" microorganism may manifest disease directly through products or antigens, or indirectly via induction of a harmful host response. In the DRF a pathogen is defined as eliciting a functional change from a commensal to a pathogenic state (Casadevall and Pirofski, 1999; Casadevall and Pirofski, 2003; Casadevall and Pirofski, 2018). Mutualism is classed as an active relationship where both species benefit. For Malassezia, they may not only survive on our skin but also may provide protection from contextually pathogenic microbes such as $S$. aureus (Li et al., 2018). Many acute skin infections have underlying microbial contributions which are improved by antimicrobial treatment (Golan, 2019). However, due to the frequency of unknown individual susceptibilities, it is often challenging to successfully satisfy Koch's postulates to prove causality by individual microbial components (Koch, 1893; Grice and Dawson, 2017). It is therefore important to delineate the context of microbial interactions with skin disease outcomes. Functional interactions can be scenarios where (i) the skin microbiota is a direct cause, (ii) the skin microbiota is altered by changes in the skin and hence generate a deleterious host response, exacerbating the situation, or (iii) where the microbiota is uninvolved. Differentiating these functional interactions is complex and for Malassezia a still developing research area.

\section{MALASSEZIA INTERACTIONS WITH SKIN AND THEIR ROLE AS A COMMENSAL}

Most metagenomic datasets reveal that microbial communities in different skin ecosystems are determined by topography and driven by water (sweat), oil (sebum), or other temporally stable attributes (Findley et al., 2013; Oh et al., 2016). Malassezia are enriched in sebaceous zones, particularly breast, back, and head, due to the abundance of the lipid nutrient source (Findley et al., 2013; Jo et al., 2017). Malassezia density is associated with the maintenance of skin health (Ashbee and Evans, 2002; Prohic et al., 2016), and Malassezia are the most abundant fungi identified at eleven core body sites, all except those on the foot. $M$. restricta and M. globosa are by far the most abundant on human skin, with other species occurring at much lower frequency (Findley et al., 2013).

In addition to body site, age plays a role in shaping the skin mycobiome. During gestation, the fetus is exposed to microbes from the placenta, fetal membranes, amniotic fluid, and umbilical cord (Pelzer et al., 2017). Immediately after birth, early skin colonization is influenced by vernix caseosa, a multi-component defense system (anti-microbial sebum) composed of cellular contents, water, lipids, and proteins produced by fetal sebaceous glands during the third trimester (Pickens et al., 2000; Tollin et al., 2005; Michalski et al., 2017; Szabo et al., 2017). Neonates born through vaginal delivery acquire microbial communities from the birth canal and vagina, resembling their mother's vaginal microbiota, where neonates born via cesarean section have skin microbial communities similar to the mother's skin surface (Dominguez-Bello et al., 2010; Oh et al., 2010; Aagaard et al., 2014; Dunn et al., 2017; Georgountzou and Papadopoulos, 2017). Malassezia colonization occurs immediately after birth, when neonatal sebaceous glands are active, being driven by maternal hormones which cross the placental barrier with a progression over the first few months of life to more closely resemble the adult microbiome assemblage (Ashbee and Evans, 2002; Bernier et al., 2002; Ayhan et al., 2007; Nagata et al., 2012). The succession of mycobiome during birth within individual infants is variable either due to mothers vaginal mycobiome or vertical transmission depending on mode of delivery and environmental impact such as caregivers and other sources (Ashbee and Evans, 2002; Bernier et al., 2002; Ward et al., 2018). In contrast to the mother's skin Malassezia colonization, infant skin only contains two percent relative abundance shown by either sequencing, PCR, or culturebased approaches. Despite the higher abundance in mother's skin, cesarean compared to vaginally born infants have lower Malassezia abundance. The reasons are currently unknown but could be biological, environmentally influenced, or a reported technical bias of Internal Transcribed Spacer (ITS) 2 region amplification (Anna and Bazzicalupoa; Bellemain et al., 2010).

As Malassezia are lipid dependent colonizers, their skin abundance would be hypothesized to follow the level of sebaceous gland activity and hence lipid level on skin (Ro and Dawson, 2005). Soon after birth (3-6 months), the sebaceous glands become dormant, and Malassezia revert to a low abundance. With the onset of puberty, increased lipid levels in 
sebaceous regions result in a concomitant increase in Malassezia abundance (Ro and Dawson, 2005; Prohic et al., 2016). Comparison of skin fungal communities between healthy children and adults showed that Malassezia predominates on adults while in children $($ age $<14)$ Malassezia were present but at lower abundance, and with a more diverse fungal community including Eurotiomycetes and common dermatophytes (Jo et al., 2016). This observation of fungal ecological dynamics may partly be responsible for the prevalence or severity of common skin disorders seen more frequently in children. Together this points to a key protective role of Malassezia when fully occupying the skin niche.

\section{IMMUNE EDUCATION, HOST TOLERANCE, AND THE RESPONSE TO MALASSEZIA}

The skin is reliant on commensal microbiota to "train" the immune system and develop appropriate tolerance, host defense mechanisms, and immunity against invading pathogens. Dynamic signals from commensals during early development are used by the immune system to provide heterologous defense mechanisms (Naik et al., 2015). These host interactions are skin-specific, and a resident immune cell population is recruited for establishing innate and adaptive responses in the periphery. One of the foremost factors for skin-microbiota coexistence is host immune tolerance, as shown in Figure 2. Tolerance is established after birth, maintained throughout life, and is defined as the capability of the host to suppress the active immune response against itself and certain microbes. The microbes in turn also have mechanisms to evade skin antimicrobial defenses and co-exist with skin (Zhang and Gallo, 2016). There is a significant body of literature, reviewed in brief here, regarding the role of the skin microbiome on normal immune development. However, little is known about the specific role of Malassezia. This will be an important area for future research.

Fetal immune development begins as early as nine to fifteen weeks with formation and maturation of multiple cell types including B and T lymphocytes (Hayward, 1983). The fetus
A

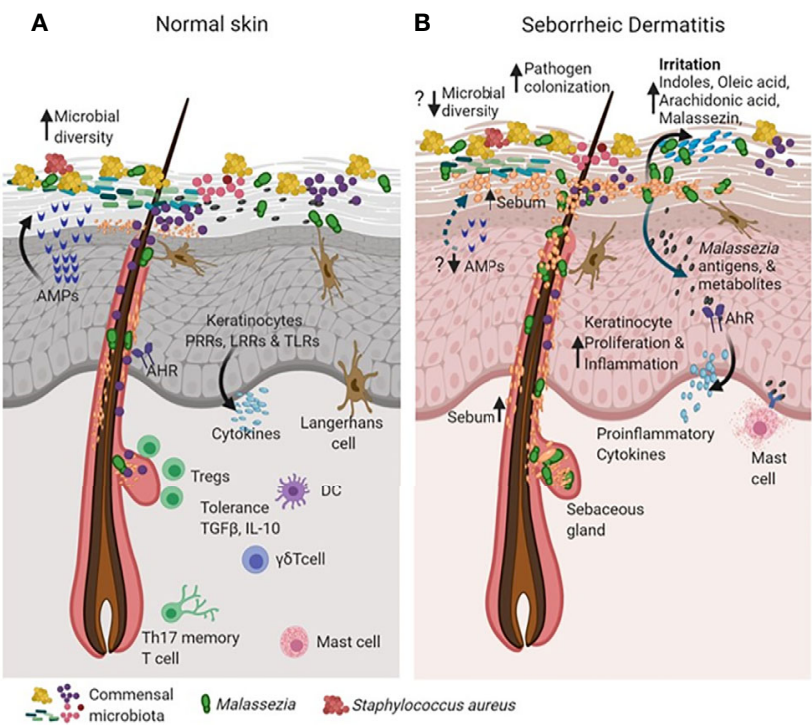

C

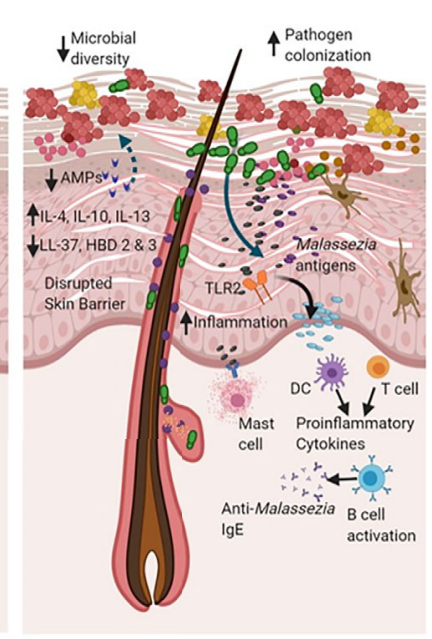

FIGURE 2 | Cross talk between skin and microbiota in healthy and diseased skin states (such as seborrheic dermatitis and atopic dermatitis). The skin and the immune system evolve together with resident microorganisms to establish commensal microbial relationships (for example, Malassezia in green). In the healthy state (A), skin maintains high microbial diversity when compared to active disease states in seborrheic dermatitis (SD) and atopic dermatitis (AD) as shown in (B, C). Keratinocytes sense microbial population through recognition of microbial pathogen-associated molecular patterns (PAMPs) motifs via their pattern recognition receptors (PRR's), Leucine rich repeat (LRR's) containing receptors and Toll-like receptors (TLR's) as shown in (A). The binding of PAMPs to PRRs, LRRs and TLRs triggers innate immune responses, resulting in the secretion of antimicrobial peptides that can rapidly inactivate a diverse range of pathogenic microorganisms, including fungi, bacteria and parasites. The Langerhans cells interact with microbial antigens in the epidermis to detect barrier breach and maintain homeostasis (A). The skin tolerance is dependent on regulatory T cells, a subset of lymphocytes infiltrate skin, concomitant with hair follicle and skin microbial colonization in based on cytokines TGF-Beta and IL-10 (A). In SD, alterations in sebum content creates favorable conditions for expansion of Malassezia as the dominant species that may cause the disease (B). Increased Malassezia colonization initiates specific utilization of stratum corneum fatty acids that are converted into by-products such as oleic acid, arachidonic acid which irritates and causes inflammation in the skin. Irritants such as indole and Malassezin could increase keratinocyte (KC) proliferation and induce inflammation (B). Accumulation of histamine in the SD lesions is suggestive of mast cell degranulation (B). In AD there is increased pathogen colonization that causes probable decreased commensal microbial diversity and a defective skin barrier(C). Malasszeia and other pathogens could stimulate sub epidermal layers and releases antigens which are recognized by TLR2 receptors feedback to DC or T cell population which stimulates immune response The disrupted skin barrier allows microbial entry in to skin which probably increases cytokines IL-4, IL-10 and IL-13 levels. Circulating anti- Malassezia IgE has been reported in $A D(\mathbf{C})$. The figure was created using Biorender.com. 
maintains a high Th2-biased immune system to prevent proinflammatory Th1-type alloimmune responses to maternal tissues (Philbin and Levy, 2009), but acquires the ability to produce IgG and IgM antibodies at 10 weeks gestation with IgG levels increasing till 22 weeks. The neonates undergo extreme physical and physiological changes at birth, with the skin surface experiencing a drastic shift from aqueous and sterile to dry with a high load of microbial antigens (Hoeger and Enzmann, 2002). The high Th2 dependent-IL6 cytokine levels, formed in the prenatal stage, shield against microbial infections, and these antigens are cleared at birth (Georgountzou and Papadopoulos, 2017).

Dynamic signals from commensals during early development are used by the immune system to provide heterologous defense mechanisms. The evolutionary interaction between cutaneous commensal microbiota and the skin immune system involves changing antigen signals to calibrate immunity against pathogens (Naik et al., 2015; Quaresma, 2019). From the time of birth, the skin microbiota develops as a highly diverse and dynamic ecology which undergoes remodeling due to host and environmental factors and aids in immune education (Grice et al., 2009; Kong and Segre, 2012). However, host tolerance is established in the early phases of immunity development immediately after birth. During this period skin regulatory $\mathrm{T}$ cells (Tregs) establish immune tolerance to commensal microbes, preserve homeostasis with skin microbiota, and protect against pathogens (Belkaid et al., 2002). In neonates, there is a steep influx of Tregs into skin within the first two weeks, to mediate tolerance specific to the commensal microbiota (Scharschmidt et al., 2015; Ali and Rosenblum, 2017). As Malassezia are among the major commensal fungi in neonates, it can be hypothesized that they may also induce and establish specific tolerance pathways in the skin involving Tregs (Figure 2).

In healthy skin, Malassezia exist as a commensal and benignly interact with keratinocytes and the immune system, as they reside mainly on the outer skin surface and the follicular infundibulum (Sanmiguel and Grice, 2015; Mittermann et al., 2016). Malassezia are detected by the host immune system through keratinocytes and various immune cell populations. The Malassezia cell wall components $\beta$ - $(1,6)$-glucans, glycolipids, and glycoproteins are recognized by proline rich region (PRR) motifs present in Dectin-2 and Macrophage inducible $\mathrm{Ca} 2+$-dependent lectin receptor (Mincle) host cell membrane bound CLR (C-type Lectin) receptors in multiple immune cell types (Ishikawa et al., 2013; Dambuza and Brown, 2015; Underhill and Pearlman, 2015; Sparber and LeibundgutLandmann, 2017). Langerin, a PRR expressed on epidermal Langerhans cells and a subset of dermal DCs, can recognize beta-glucans expressed on the Malassezia cell wall (De Jong et al., 2010; Tateno et al., 2010)(de Jong Mol Immunol 2010; Tateno J Biol Chem 2010). However, what roles these (and other PRRs) play in Malassezia-induced commensalism, inflammation, and adaptive immunity is currently not well understood.

Host innate immune activity to Malassezia has been well documented with various in vitro studies in human keratinocytes based on secretion of proinflammatory cytokines, chemokines and AMPs. M. furfur, M. globosa and $M$. restricta induced increase in expression of Toll-like receptor 2 (TLR-2), IL-8, Human beta-defensin 2 (HBD-2), HBD-3 suggests their role in skin protection. (Baroni et al., 2006; Donnarumma et al., 2014; Georgountzou and Papadopoulos, 2017). These cytokines and chemokines recruit immune cells to skin sites with minimal or compromised barrier, such as the follicle infundibulum, where Malassezia may be directly exposed to keratinocytes, tissue resident dendritic cells (DCs), macrophages, myeloid cells and $\gamma \delta$-T cells (Sparber and Leibundgut-Landmann, 2017). Malassezia can inhibit phagocyte responses to Toll-like receptor (TLR) stimulation and contribute to cutaneous invariant $\gamma \delta \mathrm{T}$ cell homeostasis through specific indole metabolites and AhR receptor signaling in the skin (Kadow et al., 2011; Vlachos et al., 2012). A murine skin infection model indicates Malassezia can induce Th17 immunity (IL-23/ 17 axis). In healthy human skin, Malassezia are also known to modulate the inflammatory cytokine response of CCR $6^{+}$Th17 memory T cells (Sparber et al., 2019). It is not clear how Malassezia mediates an immune response for either a commensal or inflammatory state in human skin.

Innate immune activation in skin enhances the adaptive immune response (Holt and Jones, 2000). Generally, adaptive immune responses are stronger in Malassezia-associated diseases, but their status during commensalism is less clear. Emerging evidence also indicates that innate lymphoid cells (ILCs) respond directly to skin fungal populations by producing IL-17 cytokine (Gladiator and LeibundgutLandmann, 2013; Gladiator et al., 2013). To substantiate the immune response, Malassezia-specific immunoglobulins IgG, $\operatorname{IgM}$, IgE, and IgA have also been identified in healthy human sweat and shown to coat Malassezia on the skin surface (Page and Remington, 1967; Forstrom et al., 1975; Metze et al., 1991; Cunningham et al., 1992). In summary, although there are studies beginning to describe the immunological response to Malassezia as commensals, further studies are required to elucidate precise mechanisms.

\section{MALASSEZIA AND SKIN DISEASE}

Malassezia have now been associated with numerous skin diseases (Gaitanis et al., 2013; Harada et al., 2015; Prohic et al., 2016; Limon et al., 2017; Saunte et al., 2020). These skin conditions are either caused, or exacerbated by, alterations by Malassezia in a changing skin environment. Malassezia normally exist as a skin commensal without inflicting disease, suggestive of contextual pathogenesis. One possible mechanism of Malassezia mediated skin disease is host genetic susceptibility (Deangelis et al., 2005). Skin barrier defects, for example, may change microbiota composition and/or behavior, leading to a corresponding immune inflammatory response. There are two modes by which Malassezia interact with the skin. One is direct, where specific Malassezia metabolites introduce physiological 
changes such as irritation. The second is indirect, where immune or allergic pathways are activated and manifest as inflammation (Grice and Dawson, 2017). One emergent challenge is to decipher the role of Malassezia as a cause or consequence in its multifaceted interaction with the skin. Malassezia can cause hypo- or hyper-pigmented non-inflammatory lesions through interaction with melanocytes, and with mild barrier defects can cause pityriasis versicolor, a common skin infection. Often Malassezia metabolites trigger a scalp inflammatory response causing dandruff and in severe situations seborrheic dermatitis, and can invade and inflame hair follicles to cause folliculitis (Theelen et al., 2018). In other inflammatory skin conditions, such as atopic dermatitis and psoriasis, there is increasing evidence about the role of Malassezia. As host susceptibility is often a prerequisite for fungal pathogenicity, it remains important for mechanistic investigational studies to be performed longitudinally in susceptible individuals, as important pathogenic mechanisms may well be present in non-susceptible individuals and confound parallel group studies by not inducing the disease phenotype.

\section{Malassezia and Childhood Skin Infections}

New-born fungal infections are usually topical with mild symptoms. However, in immune compromised or prematurely born infants', skin resident Malassezia may spread into to blood circulation and disseminate as sepsis, with serious and often lethal consequence. The initial Malassezia colonization may cause hypersensitivity reactions in neonatal face, scalp, and neck skin with non-follicular papulopustular eruptions referred to as neonatal acne or sebaceous miliria. It is not clear how these eruptions spontaneously resolve, but they usually do so within weeks. Neonatal and infantile seborrheic dermatitis associated with $M$. furfur shows a scaling scalp, 'cradle cap' phenotype and is treated by applying ketoconazole shampoo or petrolatum gently on scalp skin or affected area (Wananukul et al., 2005; Zuniga and Nguyen, 2013). Low birth weight infants are also susceptible to Malassezia skin infections and these infants are reported to have high fungal load (Speer et al., 1976; Sperling et al., 1988; Ng, 1994; Sohn et al., 2001; Kaufman and Fairchild, 2004). Proposed mechanisms for preterm neonatal skin and systemic infections involves factors such as the developing fragile skin structure having an incomplete barrier, an under-developed immune system, and microbial transmission from caregivers and hospital sources. Other clinical manifestations of infants of premature births are invasive Malassezia infections through catheters in neonatal intensive care units (NICU) (Shek et al., 1989; Pedrosa et al., 2018; Chow et al., 2020). At the onset of puberty there is increased activity of sebaceous glands and lipid content predominantly in facial, scalp and trunk skin. This favors the growth of specific lipophilic microbial populations such as $C$. acnes and Malassezia. However, it is not clear which biological factors, including changes in skin microbiota, are causative for acne vulgaris during adolescence (Common et al., 2019; Ramasamy et al., 2019).

\section{A Role for Malassezia in Pityriasis Versicolor}

Pityriasis versicolor (PV), also called Tinea versicolor, is a mild, chronic, superficial fungal infection and frequently occurs in children and adolescents when sebaceous activity is maximum. The lesions appear as hyper- or hypo-pigmented (discolored patches), mostly around the trunk and shoulders. Common clinical presentations are mild itch and scaling in affected areas (Gordon, 1951; Gaitanis et al., 2013). This mild cosmetic disease is usually more active in hot and humid weather conditions than temperate climates. Malassezia are known to cause PV (Gupta et al., 2002; Crespo-Erchiga and Florencio, 2006). To date $M$. furfur, M. globosa and M. sympodialis are the most commonly identified species in PV (Saadatzadeh et al., 2001), but due to the numerous changes in Malassezia nomenclature and the recent identification of many new species it remains unclear if any specific species is causal for PV. Malassezia usually exist as individual spherical yeast, however in PV they become mycelial with profuse hyphal growth and abnormal expansion in the affected site. Interestingly, histopathological staining from skin biopsies shows milder signs of skin barrier defects and no sign of inflammation despite the heavy fungal load. It is possible that Malassezia take advantage of a compromised skin barrier and the mycelial form can go in search of a nutrient rich skin layer (Saadatzadeh et al., 2001). It is not clear how and why there is minimal inflammation despite the increased mycelial form and fungal load. Humoral specific IgG response toward M. furfur antigens has been reported for PV (Silva et al., 1997). Although PV could be treated by specific antifungal treatments there is high risk of relapse at up to $80 \%$, which severely impacts the patients quality of life (Theelen et al., 2018).

\section{Direct Pathogenesis: Malassezia in Seborrheic Dermatitis and Dandruff}

Seborrheic dermatitis and Dandruff (D) are skin conditions found in sebaceous areas with hair. Dandruff is restricted to the scalp and involves itchy, flaking skin without visible inflammation, and is considered a mild non-inflammatory form of SD (Priestley and Savin, 1976; Danby et al., 1993; Warner et al., 2001). SD is a common chronic relapsing inflammatory skin disorder characterized by greasy scales with erythematous skin and exofoliative scaling (oily-yellow desquamation) on the scalp, which may extend to face, ears and upper chest associated with pruritus (Borda and Wikramanayake, 2015). Triggering factors include stress and cold, dry weather (Gary, 2013; Borda and Wikramanayake, 2015). The prevalence is higher in men than women, potentially due to hormonal influence by androgens (Islamoglu, 2019). However, this may also be a result of differences in grooming practices between genders. Malassezia have been identified and correlated to SD and D phenotypes, with $M$. globosa, M. restricta, $M$. dermatis and $M$. furfur associated with these conditions (Nakabayashi et al., 2000; Gupta et al., 2001; Gemmer et al., 2002; Sugita et al., 2002; Kim, 2009). There are three basic etiologic factors for SD and D; 
Malassezia, sebaceous activity, and individual or host susceptibility (Deangelis et al., 2005; Ro and Dawson, 2005). Intrinsic host factors, such as composition of sebum and defective epidermal barrier, likely have an effect on Malassezia activity (density, lipase expression and nutrient utilization, immune stimulatory metabolites) that elicits the host inflammatory response. Metabolites such as oleic acid, arachidonic acid, malassezin, and indole-3-carbaldehyde act as skin irritants and are implicated in keratinocyte proliferation and inflammation as shown in Figure 2. The causative role of Malassezia in SD and D may be assessed through Koch's postulates (Koch, 1893). As Malassezia are found on all humans, Koch's first postulate cannot be fulfilled (Mcginley et al., 1975). However, it remains unclear whether there are Malassezia strain level differences between healthy and D or SD skin that manifest the disease. It is also not known whether the same Malassezia strain(s) that exist as commensals in healthy skin contextually become pathogenic due to unknown host environment and susceptibility factors. However, removal of Malassezia using antifungals improves $\mathrm{D}$ and SD, while removal of bacteria does not, and removal of both bacteria and fungi provides a similar benefit to the removal of fungi alone (Vanderwyk, 1964; Vanderwyk, 1967; Leyden et al., 1976). Furthermore, reintroduction of resistant " $P$. ovale" (likely $M$. globosa) during application of an antifungal (nystatin) are able to induce D and SD flaking (Gosse, 1969). Finally, a specific Malassezia metabolite, oleic acid, induces a D like desquamation when applied to scalp free from Malassezia and flaking (in individuals previously determined to be susceptible to D and SD) (Ro and Dawson, 2005). These observations fulfill three of four Koch's postulates and clearly establish the pathogenic role of Malassezia in causing D and SD (Gran et al., 2020). The mechanisms of individual susceptibility to D and SD remains unclear, but host genetics implicate immune response (ACT1, C5, IKBKG/NEMO, STK4) and epidermal differentiation (ZNF750). However, it is still not known how disruption to these genetic factors is related to the clinical presentation of D and SD (Jacobs and Miller, 1972; Evans et al., 1977; Mancini et al., 2008; Abdollahpour et al., 2012; Crequer et al., 2012; Nehme et al., 2012; Boisson et al., 2013; Halacli et al., 2015; Karakadze et al., 2018).

\section{Malassezia in Atopic Dermatitis: Pathogenesis or Mutualism?}

Atopic dermatitis (AD) and psoriasis are characterized by chronic skin inflammation due to multiple genetic, immune and environmental factors (Bjerre et al., 2017; Weidinger et al., 2018; Nowicka and Nawrot, 2019; Langan et al., 2020). The majority of $\mathrm{AD}$ patients have skin barrier dysfunction either due to mutations in genes such as filaggrin and tight junctions or from a more generalized disruption from the presence of Th2 cytokines (Palmer et al., 2006; Sandilands et al., 2009; Jungersted et al., 2010; Rerknimitr et al., 2017; Drislane and Irvine, 2020). The disruption is similar in both instances with a compromised barrier as demonstrated by increased trans-epidermal water loss, high $\mathrm{pH}$, reduced stratum corneum hydration, and altered microbiota (Yang et al., 2020). Increased percutaneous sensitization from microbial products or allergens then produces a vicious cycle stimulating host immunity with resulting dryness, itching and erythema that often progresses into lesional flares and infections (De Benedetto et al., 2012; Lunjani et al., 2018). The incidence of AD is approximately $15 \%$ to $20 \%$ of children and up to $10 \%$ of adults with an age specific disease pattern (Eichenfield et al., 2014; Nutten, 2015). The skin microbiome is strongly associated in pathogenesis of AD with an over growth of Staphylococcus aureus at the infected lesions and a distinct microbial configuration in non-lesional skin including alterations in Malassezia species (Leyden et al., 1974; Kong et al., 2012; Kobayashi et al., 2015; Chng et al., 2016).

The role of Malassezia in AD is supported by both antifungal treatments reducing the severity of symptoms and that application of Malassezia extracts or recombinant Malassezia antigens on $\mathrm{AD}$ subjects exacerbates the phenotype (Zargari et al., 2001; Johansson et al., 2003; Brodska et al., 2014; Glatz et al., 2015; Prohic et al., 2016) (Figure 2). Malassezia are frequently isolated from and associated with $\mathrm{AD}$, with $M$. globosa and M. restricta found more frequently followed by $M$. sympodialis and M. furfur (Sugita et al., 2001; Amaya et al., 2007; Kaga et al., 2011). However, one study reported that AD patients yielded exclusively M. sympodialis isolates (Sandstrom Falk et al., 2005; Jagielski et al., 2014). One possible explanation why Malassezia may be in lower abundance on $\mathrm{AD}$ skin is the reduced lipid content associated with the dry skin phenotype (Pilgram et al., 2001; Chng et al., 2016; Theelen et al., 2018). In AD the susceptibility of host to Malassezia infection has also been associated with a cytokine gene polymorphism and clinical outcome (Jain et al., 2017).

Malassezia are even more strongly implicated in development and persistence of a specific subset of adult head and neck eczema, proposed to be caused by Malassezia allergens (Saunte et al., 2020). This subset of patients responds to oral or topical antifungal therapy and have circulating antibodies to multiple Malassezia antigens (Scheynius et al., 2002). While the subgroup and antigens were initially found with M. sympodialis antigens (Mala S1-9), antigens to other species have also come to light (Andersson et al., 2003). Malassezia antigens MGL 1304 (M. globosa), Mala s 8, Mala s 13 (M. sympodialis), and Mala r 8 (M. restricta) have now been shown to be released through Malassezia nanovesicles due to the increased skin $\mathrm{pH}$ in $\mathrm{AD}$ (Selander et al., 2006; Gehrmann et al., 2011; Kohsaka et al., 2018). The antigenic protein MGL-1304 is involved in histamine release and implicated as a component of the $\mathrm{AD}$ pathogenesis (Kohsaka et al., 2018). These antigenic proteins are found in sweat, and can cause sweat allergy and an IgE specific AD skin immune response (Hiragun et al., 2013). It is also known that the IgE sensitization profile to skin commensal M. sympodialis and specific allergens from the bacterial pathogen $S$. aureus differ between moderate and severe AD patients (Mittermann et al., 2016). One other $\mathrm{AD}$ subject sub-group has a $\mathrm{CD}^{+} \mathrm{T}$ cell 
population specifically reacting to Malassezia thioredoxin antigen (Mala s 13). Mala S 13 is a homolog of human thioredoxin, and the $\mathrm{CD} 4^{+} \mathrm{T}$ cells cross react with human thioredoxin, leading to $\mathrm{AD}$ skin inflammation. A similar triggering mechanism is attributed to Mala S 11, manganese dependent superoxide dismutase (Vilhelmsson et al., 2007; Balaji et al., 2011).

The disrupted skin barrier can provide a constant source for Malassezia and its allergens to enter the skin and interact with TLR2 receptors on DCs and keratinocytes. Specific proinflammatory cytokines and Malassezia specific IgE antibodies are produced through $\mathrm{T}$ cell response and $\mathrm{B}$ cell activation. The mast cells and DCs also contribute to skin inflammation sustained by cross reacting auto reactive $\mathrm{T}$ cells. In $\mathrm{AD}$ patients the increased levels of cytokines IL-4, IL-10 and IL-13 suggest inflammatory response and these cytokines are known to reduce the levels of antimicrobial peptides such as Cathelicidin (LL-37) and Human beta-defensins 2 and 3, as well as and skin barrier proteins filaggrin, loricrin and involucrin produced by keratinocytes (Figure 2; (Mcgirt and Beck, 2006; Howell et al., 2007; Kim et al., 2008). The growth of pathogens such as Staphylococcus aureus and their biofilms in AD skin is probably favored due to lack of abundance of Malassezia and reduction of human defensins (Glatz et al., 2015; Chng et al., 2016). Malassezia is also known to inhibit the growth of S. aureus biofilms through secretion of specific proteases, suggesting its possible role in healthy and AD skin (Li et al., 2018). Malassezia antigens are also responsible for activation of NLRP3 inflammasome in DCs and can trigger production of IL-1 $\beta$, IL4, IL-5, IL-13 and IL-18 cytokines in vitro (Kistowska et al., 2014). A number of these cytokines contribute to inflammation in $\mathrm{AD}$ skin as well as other allergic diseases, however, it is not clear whether Malassezia antigens are specifically expressed in AD skin or healthy subjects. Additionally, a specific subset of Th17 memory T cells is elicited to Malassezia in AD patients aggravating inflammation directly dependent on IL-17 (Sparber et al., 2019). Taken together, there is mounting evidence that Malassezia have a role in $\mathrm{AD}$. The specific Malassezia contribution to the $\mathrm{AD}$ phenotype is not clear and interactions could occur via cell wall, cell membrane or lipid metabolite components that stimulate an immune response. However, what has been shown is that antifungals are effective in reducing $\mathrm{AD}$ severity, and this should be further explored (Kolmer et al., 1996; Nikkels and Pierard, 2003).

\section{Malassezia in Psoriasis: Evolving to a Pathogenic Relationship in Susceptible Individuals?}

Psoriasis affects skin, nails, and joints and is characterized by epidermal hyperproliferation and hyperkeratinisation (Perera et al., 2012; Hugh and Weinberg, 2018). Psoriasis is a T cell mediated autoimmune disease and primarily the result of a combination of genetic and environmental factors (Barker, 1998). Psoriasis (as with AD) has a strong microbial component that could drive or exacerbate the disease phenotype (Fyhrquist et al., 2019;
Hurabielle et al., 2020). Certain Malassezia species have been associated with particular subtypes of psoriasis such as $M$. japonica and M. furfur with psoriasis vulgaris and Malassezia yeasts with guttate and scalp psoriasis (Aydogan et al., 2013; Gomez-Moyano et al., 2014; Honnavar et al., 2015). Malassezia globosa is the predominant yeast found in scalp psoriatic lesions, followed by M. furfur and M. sympodialis, but as these are also the same species found on normal scalp there is little evidence they are causal in pathogenesis. However, serum analysis from psoriatic individuals has indicated antibodies against Malassezia and its antigens (Squiquera et al., 1994; Gemmer et al., 2002; Jagielski et al., 2014). In Psoriasis, interleukin 23 (IL-23)/Th17 immune axis has been identified as a major pathway (Blauvelt, 2008; Girolomoni et al., 2017; Li et al., 2020). Malassezia can also induce Th1-related cytokines in peripheral blood mononuclear cells in vitro (Kanda et al., 2002; Valli et al., 2010) and induce keratinocyte proliferation and proinflammatory cytokine production which could potentially enhance inflammation (Baroni et al., 2004). Topical and systemic antifungal treatments show marked efficacy of improvement in psoriatic lesions (Rosenberg and Belew, 1982; Farr et al., 1985; Amichai, 2004; Armstrong et al., 2016; Beck et al., 2018). In an epicutaneous psoriasis mouse model involving preexposure to Malassezia followed by Imiquimod (IMQ) there is induction of skin inflammation in a Th17-dependent manner with a transcriptome similar in profile to human psoriatic lesions. Taken together Malassezia is likely an exacerbating factor in psoriasis where antifungal treatment can lead to symptomatic improvement but is not the initiating event (Hurabielle et al., 2020). This necessitates attempting more controlled antifungal treatment strategies in psoriasis (Stehlikova et al., 2019). Further work is required to fully understand the role of Malassezia in psoriasis.

The strongest evidence that Malassezia can directly cause skin disease remains their role in $\mathrm{D}$ and $\mathrm{SD}$, where it is clear they play a causal role (Grice and Dawson, 2017; Theelen et al., 2018). They are also very likely to be the causative agent in several less common disorders, including PV and Malassezia folliculitis (Gupta et al., 2004). It still remains less clear as to what specific role Malassezia may have in inflammatory skin disease pathogenesis. To fully elucidate the role of Malassezia in inflammatory skin disease more longitudinal treatment-based studies are needed to elucidate the protective or pathogenic role in susceptible individuals. It is likely that strain level analysis will also aid in defining the molecular mechanisms by which Malassezia contextually interact with our skin and how to strategize fungal targeted therapy toward improving clinical outcomes.

\section{MALASSEZIA AS A PROTECTOR AGAINST SKIN PATHOGENS: MUTUALISM?}

Skin barrier homeostasis is maintained in part due to multikingdom microbial communities' protective roles against pathogens (Byrd et al., 2018). A number of bacterial species have now been shown to provide a protective and synergistic 
relationship that maintains skin homeostasis (Nakatsuji et al., 2017). It has been hypothesized that the skin fungal mycobiome, primarily Malassezia, can protect human skin through its large biomass and spatial-temporal expansion. Malassezia metabolize sebum and produce short chain fatty acids (SCFA), such as azelaic acid, which are known to have dual antibacterial and anti-mycotic properties (Brasch and Christophers, 1993). Moreover, Malassezia mediated esterification of medium-chain fatty acids generate ethyl ester derivatives with in vitro antimycotic activity (Mayser, 2015). M. globosa secreted aspartyl protease 1 (MgSAP1) has been shown in vitro to disrupt biofilm formation of Staphylococcus aureus via hydrolysis of S. aureus protein-A (Li et al., 2018). In AD associated microbiomes, there is significant reduction of Malassezia as a genus and specifically M. globosa resulting in a potentially decreased protective function which could otherwise be restricting $S$. aureus pathogenicity (Chng et al., 2016).

\section{CONCLUSION}

Malassezia are now known to cause skin and scalp disorders, but there remain numerous gaps in the mechanistic understanding of how body site microenvironments affect multi-kingdom skin microbiota composition and function in both healthy homeostasis and disease states. To reach this end goal of defining the role of Malassezia as commensal, pathogen, or mutualist we still need to rationalize differences between detection methodologies. Although there is ongoing, rapid advancement in sequencing technologies and metagenomics analysis, it is not yet clear why there is such a large discrepancy between results obtained with cultures, ITS, and metagenomics. It is imperative that future microbiome studies, including any Malassezia mediated skin or systemic disease, needs appropriately controlled, robust, and reproducible detection methods which consider and balance both new, cutting edge sequencing techniques and established, well vetted technologies. Also, Malassezia have had multiple confusing changes in nomenclature and continuing expansion of the known species, making tracking of the primary literature challenging and assignment of pre-1998 activities to current strains nearly impossible (Theelen et al., 2018). As recent work has shown divergent function between even closely related species and strains, care must be taken in strain identification and assignment of function (Chng et al., 2016; Li et al., 2018). Additionally, many current studies investigating the relationships between microbe and host are limited to parallel group studies of specific pathways in target diseases, limiting understanding of molecular mechanisms that initiate or exacerbate disease progression. Mode of disease onset, function of the skin microbiota, and their role in healthy homeostasis will need to be investigated by implicit longitudinal study design, with appropriate comparison of severity and treatment stages (Grice and Dawson, 2017). These multiple factors have limited our current understanding of the role of mycobiota in healthy skin homeostasis.

In conclusion, the relationship between Malassezia and their human host is complex, varies with body site, age, and host susceptibility, and can be in any given circumstance a commensal, pathogenic, or mutualistic relationship. It is important for future clinical studies to account for intrapersonal anatomical variations in the skin microbiota, individual susceptibility, gender, age, seasonality, and ethnicity. Detailed information should also be included to capture the various stressors and perception of skin health or disease, which may promote endocrine and metabolic host changes within the cutaneous microenvironments. Full analysis of these variations will help to delineate the direct influence of microbial alterations in homeostasis of healthy skin and to develop understanding of solid causal relationships.

An improved understanding of the host-Malassezia relationship offers tremendous potential for development of treatments to improve skin health outcomes. There are opportunities to develop mycobiome targeted solutions using prebiotic or post-biotic metabolites with the potential to restore healthy skin microbiome and functional attributes such as barrier, dryness, inflammation, and reverse dysbiosis. While most studies to date describe bacterial interactions, it is crucial for future endeavors to address the mechanistic processes between fungal-fungal, inter-kingdom communities, and microbe-host for skin health and disease (Arvanitis and Mylonakis, 2015; Tipton et al., 2018; Zhang et al., 2018). Although there are now an increasing number of detailed studies that demonstrate the mycobiota's role in commensal and disease states, a substantial knowledge gap remains in understanding fungal virulence determinants and requires further attention.

\section{AUTHOR CONTRIBUTIONS}

All authors planned the review, read, and approved the final version. SHVC and RS wrote the initial draft. All authors contributed to the article and approved the submitted version.

\section{FUNDING}

This work was supported by funding from Agency for Science, Technology and Research (A ${ }^{\star}$ STAR) and $A^{\star}$ STAR BMRC EDB IAF-PP grants_H17/01/a0/004 "Skin Research Institute of Singapore" and H18/01a0/016 "Asian Skin Microbiome Program".

\section{ACKNOWLEDGMENTS}

We thank our collaborators Yuen In Lam, Bart Theelen, and Ianiri Giuseppe for invaluable feedback and discussions on the phylogenetic tree. 


\section{REFERENCES}

Aagaard, K., Ma, J., Antony, K. M., Ganu, R., Petrosino, J., and Versalovic, J. (2014). The placenta harbors a unique microbiome. Sci. Transl. Med. 6, 237ra265. doi: 10.1126/scitranslmed.3008599

Abdollahpour, H., Appaswamy, G., Kotlarz, D., Diestelhorst, J., Beier, R., Schaffer, A. A., et al. (2012). The phenotype of human STK4 deficiency. Blood 119, 3450-3457. doi: 10.1182/blood-2011-09-378158

Aguirre, C., Euliarte, C., Finquelievich, J., Sosa Mde, L., and Giusiano, G. (2015). Fungemia and interstitial lung compromise caused by Malassezia sympodialis in a pediatric patient. Rev. Iberoam. Micol. 32, 118-121. doi: 10.1016/ j.riam.2014.01.002

Ali, N., and Rosenblum, M. D. (2017). Regulatory T cells in skin. Immunology 152, 372-381. doi: 10.1111/imm.12791

Amaya, M., Tajima, M., Okubo, Y., Sugita, T., Nishikawa, A., and Tsuboi, R. (2007). Molecular analysis of Malassezia microflora in the lesional skin of psoriasis patients. J. Dermatol. 34, 619-624. doi: 10.1111/j.13468138.2007.00343.x

Amichai, B. (2004). Psoriasis of the glans penis in a child successfully treated with Elidel (pimecrolimus) cream. J. Eur. Acad. Dermatol. Venereol. 18, 742-743. doi: 10.1111/j.1468-3083.2004.01054.x

Andersson, A., Scheynius, A., and Rasool, O. (2003). Detection of Mala f and Mala s allergen sequences within the genus Malassezia. Med. Mycol. 41, 479-485. doi: 10.1080/13693780310001615367

Anna, L., and Bazzicalupoa, M. B. (2013). Imke Schmitt Comparison of ITS1 and ITS2 rDNA in 454 sequencing of hyperdiverse fungal communities. Fungal Ecol. 6 (1), 102-109. doi: 10.1016/j.funeco.2012.09.003

Armstrong, A. W., Bukhalo, M., and Blauvelt, A. (2016). A Clinician's Guide to the Diagnosis and Treatment of Candidiasis in Patients with Psoriasis. Am. J. Clin. Dermatol. 17, 329-336. doi: 10.1007/s40257-016-0206-4

Arumugam, M., Raes, J., Pelletier, E., Le Paslier, D., Yamada, T., Mende, D. R., et al. (2011). Enterotypes of the human gut microbiome. Nature 473, 174-180. doi: 10.1038 /nature09944

Arvanitis, M., and Mylonakis, E. (2015). Fungal-bacterial interactions and their relevance in health. Cell Microbiol. 17, 1442-1446. doi: 10.1111/cmi.12493

Ashbee, H. R., Ingham, E., Holland, K. T., and Cunliffe, W. J. (1993). The carriage of Malassezia furfur serovars A, B and C in patients with pityriasis versicolor, seborrhoeic dermatitis and controls. Br. J. Dermatol. 129, 533-540. doi: 10.1111/j.1365-2133.1993.tb00480.x

Ashbee, H. R., and Evans, E. G. (2002). Immunology of diseases associated with Malassezia species. Clin. Microbiol. Rev. 15, 21-57. doi: 10.1128/CMR.15.1.2157.2002

Aydogan, K., Tore, O., Akcaglar, S., Oral, B., Ener, B., Tunali, S., et al. (2013). Effects of Malassezia yeasts on serum Th1 and Th2 cytokines in patients with guttate psoriasis. Int. J. Dermatol. 52, 46-52. doi: 10.1111/j.13654632.2011.05280.x

Ayhan, M., Sancak, B., Karaduman, A., Arikan, S., and Sahin, S. (2007). Colonization of neonate skin by Malassezia species: relationship with neonatal cephalic pustulosis. J. Am. Acad. Dermatol. 57, 1012-1018. doi: 10.1016/j.jaad.2007.02.030

Balaji, H., Heratizadeh, A., Wichmann, K., Niebuhr, M., Crameri, R., Scheynius, A., et al. (2011). Malassezia sympodialis thioredoxin-specific T cells are highly cross-reactive to human thioredoxin in atopic dermatitis. J. Allergy Clin. Immunol. 128, 92-99 e94. doi: 10.1016/j.jaci.2011.02.043

Barker, J. N. (1998). Psoriasis as a T cell-mediated autoimmune disease. Hosp. Med. 59, 530-533.

Baroni, A., Paoletti, I., Ruocco, E., Agozzino, M., Tufano, M. A., and Donnarumma, G. (2004). Possible role of Malassezia furfur in psoriasis: modulation of TGF-beta1, integrin, and HSP70 expression in human keratinocytes and in the skin of psoriasis-affected patients. J. Cutan Pathol. 31, 35-42. doi: 10.1046/j.0303-6987.2004.0135.x

Baroni, A., Orlando, M., Donnarumma, G., Farro, P., Iovene, M. R., Tufano, M. A., et al. (2006). Toll-like receptor 2 (TLR2) mediates intracellular signalling in human keratinocytes in response to Malassezia furfur. Arch. Dermatol. Res. 297, 280-288. doi: 10.1007/s00403-005-0594-4

Batra, R., Boekhout, T., Gueho, E., Cabanes, F. J., Dawson, T. L.Jr., and Gupta, A. K. (2005). Malassezia Baillon, emerging clinical yeasts. FEMS Yeast Res. 5, 11011113. doi: 10.1016/j.femsyr.2005.05.006
Beck, K. M., Yang, E. J., Sanchez, I. M., and Liao, W. (2018). Treatment of Genital Psoriasis: A Systematic Review. Dermatol. Ther. (Heidelb) 8, 509-525. doi: 10.1007/s13555-018-0257-y

Belkaid, Y., Piccirillo, C. A., Mendez, S., Shevach, E. M., and Sacks, D. L. (2002). $\mathrm{CD} 4+\mathrm{CD} 25+$ regulatory $\mathrm{T}$ cells control Leishmania major persistence and immunity. Nature 420, 502-507. doi: 10.1038/nature01152

Bellemain, E., Carlsen, T., Brochmann, C., Coissac, E., Taberlet, P., and Kauserud, H. (2010). ITS as an environmental DNA barcode for fungi: an in silico approach reveals potential PCR biases. BMC Microbiol. 10, 189. doi: 10.1186/1471-218010-189

Bernier, V., Weill, F. X., Hirigoyen, V., Elleau, C., Feyler, A., Labreze, C., et al. (2002). Skin colonization by Malassezia species in neonates: a prospective study and relationship with neonatal cephalic pustulosis. Arch. Dermatol. 138, 215-218. doi: 10.1001/archderm.138.2.215

Bjerre, R. D., Bandier, J., Skov, L., Engstrand, L., and Johansen, J. D. (2017). The role of the skin microbiome in atopic dermatitis: a systematic review. $\mathrm{Br}$. J. Dermatol. 177, 1272-1278. doi: 10.1111/bjd.15390

Blauvelt, A. (2008). T-helper 17 cells in psoriatic plaques and additional genetic links between IL-23 and psoriasis. J. Invest. Dermatol. 128, 1064-1067. doi: 10.1038/jid.2008.85

Boekhout, T., Kamp, M., and Gueho, E. (1998). Molecular typing of Malassezia species with PFGE and RAPD. Med. Mycol. 36, 365-372. doi: 10.1080/ 02681219880000581

Boekhout T, M. P., Guého-Kellermann, E., and Velegraki, A. (2010). Malassezia and the Skin. Berlin: Springer 1-311. doi: 10.1007/978-3-642-03616-3

Boisson, B., Wang, C., Pedergnana, V., Wu, L., Cypowyj, S., Rybojad, M., et al. (2013). An ACT1 mutation selectively abolishes interleukin-17 responses in humans with chronic mucocutaneous candidiasis. Immunity 39, 676-686. doi: 10.1016/j.immuni.2013.09.002

Borda, L. J., and Wikramanayake, T. C. (2015). Seborrheic Dermatitis and Dandruff: A Comprehensive Review. J. Clin. Invest. Dermatol. 3, 1-10. doi: 10.13188/2373-1044.1000019

Brasch, J., and Christophers, E. (1993). Azelaic acid has antimycotic properties in vitro. Dermatology 186, 55-58. doi: 10.1159/000247303

Brodska, P., Panzner, P., Pizinger, K., and Schmid-Grendelmeier, P. (2014). IgEmediated sensitization to malassezia in atopic dermatitis: more common in male patients and in head and neck type. Dermatitis 25, 120-126. doi: 10.1097/ DER.0000000000000040

Byrd, A. L., Belkaid, Y., and Segre, J. A. (2018). The human skin microbiome. Nat. Rev. Microbiol. 16, 143-155. doi: 10.1038/nrmicro.2017.157

Cabanes, F. J. (2014). Malassezia yeasts: how many species infect humans and animals? PloS Pathog. 10, e1003892. doi: 10.1371/journal.ppat.1003892

Casadevall, A., and Pirofski, L. A. (1999). Host-pathogen interactions: redefining the basic concepts of virulence and pathogenicity. Infect. Immun. 67, 37033713. doi: 10.1128/IAI.67.8.3703-3713.1999

Casadevall, A., and Pirofski, L. A. (2003). The damage-response framework of microbial pathogenesis. Nat. Rev. Microbiol. 1, 17-24. doi: 10.1038/nrmicro732

Casadevall, A., and Pirofski, L. A. (2018). What Is a Host? Attributes of Individual Susceptibility. Infect. Immun. 86, 1-12. doi: 10.1128/IAI.00636-17

Celis, A. M., Vos, A. M., Triana, S., Medina, C. A., Escobar, N., Restrepo, S., et al. (2017). Highly efficient transformation system for Malassezia furfur and Malassezia pachydermatis using Agrobacterium tumefaciens-mediated transformation. J. Microbiol. Methods 134, 1-6. doi: 10.1016/ j.mimet.2017.01.001

Chng, K. R., Tay, A. S., Li, C., Ng, A. H., Wang, J., Suri, B. K., et al. (2016). Whole metagenome profiling reveals skin microbiome-dependent susceptibility to atopic dermatitis flare. Nat. Microbiol. 1, 16106. doi: 10.1038/ nmicrobiol.2016.106

Chow, N. A., Chinn, R., Pong, A., Schultz, K., Kim, J., Gade, L., et al. (2020). Use of whole-genome sequencing to detect an outbreak of Malassezia pachydermatis infection and colonization in a neonatal intensive care unit-Californi-2016. Infect. Control Hosp. Epidemiol., 1-3. doi: 10.1017/ice.2020.419

Common, J. E. A., Barker, J. N., and Van Steensel, M. A. M. (2019). What does acne genetics teach us about disease pathogenesis? Br. J. Dermatol. 181, 665676. doi: 10.1111/bjd.17721

Crequer, A., Picard, C., Patin, E., D’amico, A., Abhyankar, A., Munzer, M., et al. (2012). Inherited MST1 deficiency underlies susceptibility to EV-HPV infections. PloS One 7, e44010. doi: 10.1371/journal.pone.0044010 
Crespo-Erchiga, V., and Florencio, V. D. (2006). Malassezia yeasts and pityriasis versicolor. Curr. Opin. Infect. Dis. 19, 139-147. doi: 10.1097/01.qco. 0000216624.21069.61

Cunningham, A. C., Leeming, J. P., Ingham, E., and Gowland, G. (1990). Differentiation of three serovars of Malassezia furfur. J. Appl. Bacteriol. 68, 439-446. doi: 10.1111/j.1365-2672.1990.tb02894.x

Cunningham, A. C., Ingham, E., and Gowland, G. (1992). Humoral responses to Malassezia furfur serovars A, B and $\mathrm{C}$ in normal individuals of various ages. $\mathrm{Br}$. J. Dermatol. 127, 476-481. doi: 10.1111/j.1365-2133.1992.tb14843.x

Dambuza, I. M., and Brown, G. D. (2015). C-type lectins in immunity: recent developments. Curr. Opin. Immunol. 32, 21-27. doi: 10.1016/j.coi.2014.12.002

Danby, F. W., Maddin, W. S., Margesson, L. J., and Rosenthal, D. (1993). A randomized, double-blind, placebo-controlled trial of ketoconazole $2 \%$ shampoo versus selenium sulfide $2.5 \%$ shampoo in the treatment of moderate to severe dandruff. J. Am. Acad. Dermatol. 29, 1008-1012. doi: 10.1016/0190-9622(93)70282-x

De Benedetto, A., Kubo, A., and Beck, L. A. (2012). Skin barrier disruption: a requirement for allergen sensitization? J. Invest. Dermatol. 132, 949-963. doi: 10.1038/jid.2011.435

De Jong, M. A., Vriend, L. E., Theelen, B., Taylor, M. E., Fluitsma, D., Boekhout, T., et al. (2010). C-type lectin Langerin is a beta-glucan receptor on human Langerhans cells that recognizes opportunistic and pathogenic fungi. Mol. Immunol. 47, 1216-1225. doi: 10.1016/j.molimm.2009.12.016

Deangelis, Y. M., Gemmer, C. M., Kaczvinsky, J. R., Kenneally, D. C., Schwartz, J. R., and Dawson, T. L.Jr. (2005). Three etiologic facets of dandruff and seborrheic dermatitis: Malassezia fungi, sebaceous lipids, and individual sensitivity. J. Invest. Dermatol. Symp. Proc. 10, 295-297. doi: 10.1111/j.10870024.2005.10119.x

Dominguez-Bello, M. G., Costello, E. K., Contreras, M., Magris, M., Hidalgo, G., Fierer, N., et al. (2010). Delivery mode shapes the acquisition and structure of the initial microbiota across multiple body habitats in newborns. Proc. Natl. Acad. Sci. U.S.A. 107, 11971-11975. doi: 10.1073/pnas.1002601107

Donnarumma, G., Perfetto, B., Paoletti, I., Oliviero, G., Clavaud, C., Del Bufalo, A., et al. (2014). Analysis of the response of human keratinocytes to Malassezia globosa and restricta strains. Arch. Dermatol. Res. 306, 763-768. doi: 10.1007/ s00403-014-1479-1

Drislane, C., and Irvine, A. D. (2020). The role of filaggrin in atopic dermatitis and allergic disease. Ann. Allergy Asthma Immunol. 124, 36-43. doi: 10.1016/ j.anai.2019.10.008

Dunn, A. B., Jordan, S., Baker, B. J., and Carlson, N. S. (2017). The Maternal Infant Microbiome: Considerations for Labor and Birth. MCN Am. J. Matern. Child Nurs. 42, 318-325. doi: 10.1097/NMC.0000000000000373

Eichenfield, L. F., Tom, W. L., Chamlin, S. L., Feldman, S. R., Hanifin, J. M., Simpson, E. L., et al. (2014). Guidelines of care for the management of atopic dermatitis: section 1. Diagnosis and assessment of atopic dermatitis. J. Am. Acad. Dermatol. 70, 338-351. doi: 10.1016/j.jaad.2013.10.010

Evans, D. I., Holzel, A., and Macfarlane, H. (1977). Yeast opsonization defect and immunoglobulin deficiency in severe infantile dermatitis (Leiner's disease). Arch. Dis. Child 52, 691-695. doi: 10.1136/adc.52.9.691

Farr, P. M., Krause, L. B., Marks, J. M., and Shuster, S. (1985). Response of scalp psoriasis to oral ketoconazole. Lancet 2, 921-922. doi: 10.1016/S0140-6736(85) 90853-0

Findley, K., Oh, J., Yang, J., Conlan, S., Deming, C., Meyer, J. A., et al. (2013). Topographic diversity of fungal and bacterial communities in human skin. Nature 498, 367-370. doi: 10.1038/nature12171

Forstrom, L., Goldyne, M. E., and Winkelmann, R. K. (1975). IgE in human eccrine sweat. J. Invest. Dermatol. 64, 156-157. doi: 10.1111/1523-1747. ep12533312

Fyhrquist, N., Muirhead, G., Prast-Nielsen, S., Jeanmougin, M., Olah, P., Skoog, T., et al. (2019). Microbe-host interplay in atopic dermatitis and psoriasis. Nat. Commun. 10, 4703. doi: 10.1038/s41467-019-12253-y

Gaitanis, G., Velegraki, A., Mayser, P., and Bassukas, I. D. (2013). Skin diseases associated with Malassezia yeasts: facts and controversies. Clin. Dermatol. 31, 455-463. doi: 10.1016/j.clindermatol.2013.01.012

Gallo, R. L. (2017). Human Skin Is the Largest Epithelial Surface for Interaction with Microbes. J. Invest. Dermatol. 137, 1213-1214. doi: 10.1016/j.jid.2016.11.045

Gary, G. (2013). Optimizing treatment approaches in seborrheic dermatitis. J. Clin. Aesthet. Dermatol. 6, 44-49.
Gehrmann, U., Qazi, K. R., Johansson, C., Hultenby, K., Karlsson, M., Lundeberg, L., et al. (2011). Nanovesicles from Malassezia sympodialis and host exosomes induce cytokine responses-novel mechanisms for host-microbe interactions in atopic eczema. PloS One 6, e21480. doi: 10.1371/journal.pone.0021480

Gemmer, C. M., Deangelis, Y. M., Theelen, B., Boekhout, T., and Dawson, T. L.Jr. (2002). Fast, noninvasive method for molecular detection and differentiation of Malassezia yeast species on human skin and application of the method to dandruff microbiology. J. Clin. Microbiol. 40, 3350-3357. doi: 10.1128/ JCM.40.9.3350-3357.2002

Georgountzou, A., and Papadopoulos, N. G. (2017). Postnatal Innate Immune Development: From Birth to Adulthood. Front. Immunol. 8, 957. doi: 10.3389/ fimmu.2017.00957

Girolomoni, G., Strohal, R., Puig, L., Bachelez, H., Barker, J., Boehncke, W. H., et al. (2017). The role of IL-23 and the IL-23/TH 17 immune axis in the pathogenesis and treatment of psoriasis. J. Eur. Acad. Dermatol. Venereol. 31, 1616-1626. doi: $10.1111 /$ jdv. 14433

Gladiator, A., Wangler, N., Trautwein-Weidner, K., and Leibundgut-Landmann, S. (2013). Cutting edge: IL-17-secreting innate lymphoid cells are essential for host defense against fungal infection. J. Immunol. 190, 521-525. doi: 10.4049/ jimmunol.1202924

Gladiator, A., and Leibundgut-Landmann, S. (2013). Innate lymphoid cells: new players in IL-17-mediated antifungal immunity. PloS Pathog. 9, e1003763. doi: 10.1371/journal.ppat.1003763

Glatz, M., Buchner, M., Von Bartenwerffer, W., Schmid-Grendelmeier, P., Worm, M., Hedderich, J., et al. (2015). Malassezia spp.-specific immunoglobulin E level is a marker for severity of atopic dermatitis in adults. Acta Derm. Venereol. 95, 191196. doi: 10.2340/00015555-1864

Goh, J. P. Z., Ianiri, G., Heitman, J., and Dawson, T. L.Jr. (2020). Expression of a Malassezia Codon Optimized mCherry Fluorescent Protein in a Bicistronic Vector. Front. Cell Infect. Microbiol. 10, 367. doi: 10.3389/fcimb.2020.00367

Golan, Y. (2019). Current Treatment Options for Acute Skin and Skin-structure Infections. Clin. Infect. Dis. 68, S206-S212. doi: 10.1093/cid/ciz004

Gomez-Moyano, E., Crespo-Erchiga, V., Martinez-Pilar, L., Godoy Diaz, D., Martinez-Garcia, S., Lova Navarro, M., et al. (2014). Do Malassezia species play a role in exacerbation of scalp psoriasis? J. Mycol. Med. 24, 87-92. doi: 10.1016/j.mycmed.2013.10.007

Gordon, M. A. (1951). Lipophilic yeastlike organisms associated with tinea versicolor. J. Invest. Dermatol. 17, 267-272. doi: 10.1038/jid.1951.93

Gosse, R. (1969). The relationship of a nystatin-resistant strain of Pityrosporum ovale to dandruff. J. Soc. Cosmet. Chem. 20, 603-606.

Gran, F., Kerstan, A., Serfling, E., Goebeler, M., and Muhammad, K. (2020). Current Developments in the Immunology of Psoriasis. Yale J. Biol. Med. 93, 97-110.

Grice, E. A., Kong, H. H., Conlan, S., Deming, C. B., Davis, J., Young, A. C., et al. (2009). Topographical and temporal diversity of the human skin microbiome. Science 324, 1190-1192. doi: 10.1126/science.1171700

Grice, E. A., and Dawson, T. L.Jr. (2017). Host-microbe interactions: Malassezia and human skin. Curr. Opin. Microbiol. 40, 81-87. doi: 10.1016/ j.mib.2017.10.024

Guého-Kellermann, E.,. B. T., and Begerow, D. (2010). "Malassezia and the Skin : science and clinical practice," in Malassezia and the Skin, 1st edn. Eds. T. Boekhout, P. Mayser, E. Kellermann and A. Velegraki (Berlin: Springer), 2010.

Gupta, A. K., Kohli, Y., Summerbell, R. C., and Faergemann, J. (2001). Quantitative culture of Malassezia species from different body sites of individuals with or without dermatoses. Med. Mycol. 39, 243-251. doi: 10.1080/mmy.39.3.243.251

Gupta, A. K., Bluhm, R., and Summerbell, R. (2002). Pityriasis versicolor. J. Eur. Acad. Dermatol. Venereol. 16, 19-33. doi: 10.1046/j.1468-3083.2002.00378.x

Gupta, A. K., Batra, R., Bluhm, R., Boekhout, T., and Dawson, T. L.Jr. (2004). Skin diseases associated with Malassezia species. J. Am. Acad. Dermatol. 51, 785798. doi: 10.1016/j.jaad.2003.12.034

Halacli, S. O., Ayvaz, D. C., Sun-Tan, C., Erman, B., Uz, E., Yilmaz, D. Y., et al. (2015). STK4 (MST1) deficiency in two siblings with autoimmune cytopenias: A novel mutation. Clin. Immunol. 161, 316-323. doi: 10.1016/ j.clim.2015.06.010

Harada, K., Saito, M., Sugita, T., and Tsuboi, R. (2015). Malassezia species and their associated skin diseases. J. Dermatol. 42, 250-257. doi: 10.1111/13468138.12700 
Hayward, A. R. (1983). The human fetus and newborn: development of the immune response. Birth Defects Orig. Artic. Ser. 19, 289-294.

Hiragun, T., Ishii, K., Hiragun, M., Suzuki, H., Kan, T., Mihara, S., et al. (2013). Fungal protein MGL_1304 in sweat is an allergen for atopic dermatitis patients. J. Allergy Clin. Immunol. 132, 608-615 e604. doi: 10.1016/j.jaci.2013.03.047

Hoeger, P. H., and Enzmann, C. C. (2002). Skin physiology of the neonate and young infant: a prospective study of functional skin parameters during early infancy. Pediatr. Dermatol. 19, 256-262. doi: 10.1046/j.1525-1470.2002. 00082.x

Holt, P. G., and Jones, C. A. (2000). The development of the immune system during pregnancy and early life. Allergy 55, 688-697. doi: 10.1034/j.13989995.2000.00118.x

Honnavar, P., Chakrabarti, A., Dogra, S., Handa, S., and Rudramurthy, S. M. (2015). Phenotypic and molecular characterization of Malassezia japonica isolated from psoriasis vulgaris patients. J. Med. Microbiol. 64, 232-236. doi: 10.1099/jmm.0.000011

Honnavar, P., Prasad, G. S., Ghosh, A., Dogra, S., Handa, S., and Rudramurthy, S. M. (2016). Malassezia arunalokei sp. nov., a Novel Yeast Species Isolated from Seborrheic Dermatitis Patients and Healthy Individuals from India. J. Clin. Microbiol. 54, 1826-1834. doi: 10.1128/JCM.00683-16

Howell, M. D., Kim, B. E., Gao, P., Grant, A. V., Boguniewicz, M., Debenedetto, A., et al. (2007). Cytokine modulation of atopic dermatitis filaggrin skin expression. J. Allergy Clin. Immunol. 120, 150-155. doi: 10.1016/j.jaci.2007. 04.031

Hugh, J. M., and Weinberg, J. M. (2018). Update on the pathophysiology of psoriasis. Cutis 102, 6-12.

Hurabielle, C., Link, V. M., Bouladoux, N., Han, S. J., Merrill, E. D., Lightfoot, Y. L., et al. (2020). Immunity to commensal skin fungi promotes psoriasiform skin inflammation. Proc. Natl. Acad. Sci. U.S.A. 117, 16465-16474. doi: 10.1073/ pnas. 2003022117

Ianiri, G., Averette, A. F., Kingsbury, J. M., Heitman, J., and Idnurm, A. (2016). Gene Function Analysis in the Ubiquitous Human Commensal and Pathogen Malassezia Genus. mBio 7, 1-13. doi: 10.1128/mBio.01853-16

Ianiri, G., Dagotto, G., Sun, S., and Heitman, J. (2019). Advancing Functional Genetics Through Agrobacterium-Mediated Insertional Mutagenesis and CRISPR/Cas9 in the Commensal and Pathogenic Yeast Malassezia. Genetics 212, 1163-1179. doi: 10.1534/genetics.119.302329

Ianiri, G., Coelho, M. A., Ruchti, F., Sparber, F., Mcmahon, T. J., Fu, C., et al. (2020). HGT in the human and skin commensal Malassezia: A bacterially derived flavohemoglobin is required for NO resistance and host interaction. Proc. Natl. Acad. Sci. U.S.A. 117, 15884-15894. doi: 10.1073/pnas.2003473117

Ianiri, G., and Heitman, J. (2020). Approaches for Genetic Discoveries in the Skin Commensal and Pathogenic Malassezia Yeasts. Front. Cell Infect. Microbiol. 10, 393. doi: $10.3389 /$ fcimb. 2020.00393

Iatta, R., Cafarchia, C., Cuna, T., Montagna, O., Laforgia, N., Gentile, O., et al. (2014). Bloodstream infections by Malassezia and Candida species in critical care patients. Med. Mycol. 52, 264-269. doi: 10.1093/mmy/myt004

Ishikawa, T., Itoh, F., Yoshida, S., Saijo, S., Matsuzawa, T., Gonoi, T., et al. (2013). Identification of distinct ligands for the C-type lectin receptors Mincle and Dectin-2 in the pathogenic fungus Malassezia. Cell Host. Microbe 13, 477-488. doi: 10.1016/j.chom.2013.03.008

Islamoglu, Z. G. K. (2019). Second-to-fourth digit ratio and seborrheic dermatitis in males: a cross-sectional study. Bras. Dermatol. 94, 327-330. doi: 10.1590/ abd1806-4841.20198578

Jacobs, J. C., and Miller, M. E. (1972). Fatal familial Leiner's disease: a deficiency of the opsonic activity of serum complement. Pediatrics 49, 225-232.

Jagielski, T., Rup, E., Ziolkowska, A., Roeske, K., Macura, A. B., and Bielecki, J. (2014). Distribution of Malassezia species on the skin of patients with atopic dermatitis, psoriasis, and healthy volunteers assessed by conventional and molecular identification methods. BMC Dermatol. 14, 3. doi: 10.1186/14715945-14-3

Jain, C., Das, S., Ramachandran, V. G., Saha, R., Bhattacharya, S. N., and Dar, S. (2017). Malassezia Yeast and Cytokine Gene Polymorphism in Atopic Dermatitis. J. Clin. Diagn. Res. 11, DC01-DC05. doi: 10.7860/JCDR/2017/ 23948.9474

Jo, J. H., Deming, C., Kennedy, E. A., Conlan, S., Polley, E. C., Ng, W. I., et al. (2016). Diverse Human Skin Fungal Communities in Children Converge in Adulthood. J. Invest. Dermatol. 136, 2356-2363. doi: 10.1016/j.jid.2016.05.130
Jo, J. H., Kennedy, E. A., and Kong, H. H. (2017). Topographical and physiological differences of the skin mycobiome in health and disease. Virulence 8, 324-333. doi: 10.1080/21505594.2016.1249093

Johansson, C., Sandstrom, M. H., Bartosik, J., Sarnhult, T., Christiansen, J., Zargari, A., et al. (2003). Atopy patch test reactions to Malassezia allergens differentiate subgroups of atopic dermatitis patients. Br. J. Dermatol. 148, 479488. doi: 10.1046/j.1365-2133.2003.05093.x

Jungersted, J. M., Scheer, H., Mempel, M., Baurecht, H., Cifuentes, L., Hogh, J. K., et al. (2010). Stratum corneum lipids, skin barrier function and filaggrin mutations in patients with atopic eczema. Allergy 65, 911-918. doi: 10.1111/ j.1398-9995.2010.02326.x

Kadow, S., Jux, B., Zahner, S. P., Wingerath, B., Chmill, S., Clausen, B. E., et al. (2011). Aryl hydrocarbon receptor is critical for homeostasis of invariant gammadelta T cells in the murine epidermis. J. Immunol. 187, 3104-3110. doi: 10.4049/jimmunol.1100912

Kaga, M., Sugita, T., Nishikawa, A., Wada, Y., Hiruma, M., and Ikeda, S. (2011). Molecular analysis of the cutaneous Malassezia microbiota from the skin of patients with atopic dermatitis of different severities. Mycoses 54, e24-e28. doi: 10.1111/j.1439-0507.2009.01821.x

Kanda, N., Tani, K., Enomoto, U., Nakai, K., and Watanabe, S. (2002). The skin fungus-induced Th1- and Th2-related cytokine, chemokine and prostaglandin E2 production in peripheral blood mononuclear cells from patients with atopic dermatitis and psoriasis vulgaris. Clin. Exp. Allergy 32, 1243-1250. doi: 10.1046/j.1365-2745.2002.01459.x

Karakadze, M. A., Hirt, P. A., and Wikramanayake, T. C. (2018). The genetic basis of seborrhoeic dermatitis: a review. J. Eur. Acad. Dermatol. Venereol. 32, 529536. doi: $10.1111 /$ jdv.14704

Katoh, K., Kuma, K., Toh, H., and Miyata, T. (2005). MAFFT version 5: improvement in accuracy of multiple sequence alignment. Nucleic Acids Res. 33, 511-518. doi: 10.1093/nar/gki198

Kaufman, D., and Fairchild, K. D. (2004). Clinical microbiology of bacterial and fungal sepsis in very-low-birth-weight infants. Clin. Microbiol. Rev. 17, 638680. doi: 10.1128/CMR.17.3.638-680.2004

Kim, B. E., Leung, D. Y., Boguniewicz, M., and Howell, M. D. (2008). Loricrin and involucrin expression is down-regulated by Th2 cytokines through STAT-6. Clin. Immunol. 126, 332-337. doi: 10.1016/j.clim.2007.11.006

Kim, M., Cho, Y. J., Park, M., Choi, Y., Hwang, S. Y., and Jung, W. H. (2018). Genomic Tandem Quadruplication is Associated with Ketoconazole Resistance in Malassezia pachydermatis. J. Microbiol. Biotechnol. 28, 1937-1945. doi: $10.4014 /$ jmb.1810.10019

Kim, G. K. (2009). Seborrheic Dermatitis and Malassezia species: How Are They Related? J. Clin. Aesthet. Dermatol. 2, 14-17.

Kistowska, M., Fenini, G., Jankovic, D., Feldmeyer, L., Kerl, K., Bosshard, P., et al. (2014). Malassezia yeasts activate the NLRP3 inflammasome in antigenpresenting cells via Syk-kinase signalling. Exp. Dermatol. 23, 884-889. doi: 10.1111/exd.12552

Kiuchi, A., Taharaguchi, S., Hanazawa, R., Hara, M., Ikeda, T., and Tabuchi, K. (1992). Chromosome-sized DNA of Malassezia pachydermatis by pulsedfield gel electrophoresis. J. Vet. Med. Sci. 54, 1219-1220. doi: 10.1292/ jvms.54.1219

Kobayashi, T., Glatz, M., Horiuchi, K., Kawasaki, H., Akiyama, H., Kaplan, D. H., et al. (2015). Dysbiosis and Staphylococcus aureus Colonization Drives Inflammation in Atopic Dermatitis. Immunity 42, 756-766. doi: 10.1016/ j.immuni.2015.03.014

Koch, R. (1893). Ueber den augenblicklichen Stand der bakteriologischen Choleradiagnose. Z Hyg. Infekt. 14, 319-338. doi: 10.1007/BF02284324

Kohsaka, T., Hiragun, T., Ishii, K., Hiragun, M., Kamegashira, A., and Hide, M. (2018). Different hypersensitivities against homologous proteins of MGL_1304 in patients with atopic dermatitis. Allergol. Int. 67, 103-108. doi: 10.1016/ j.alit.2017.05.009

Kolmer, H. L., Taketomi, E. A., Hazen, K. C., Hughs, E., Wilson, B. B., and PlattsMills, T. A. (1996). Effect of combined antibacterial and antifungal treatment in severe atopic dermatitis. J. Allergy Clin. Immunol. 98, 702-707. doi: 10.1016/ S0091-6749(96)70106-9

Kong, H. H., Oh, J., Deming, C., Conlan, S., Grice, E. A., Beatson, M. A., et al. (2012). Temporal shifts in the skin microbiome associated with disease flares and treatment in children with atopic dermatitis. Genome Res. 22, 850-859. doi: $10.1101 /$ gr.131029.111 
Kong, H. H., and Segre, J. A. (2012). Skin microbiome: looking back to move forward. J. Invest. Dermatol. 132, 933-939. doi: 10.1038/jid.2011.417

Langan, S. M., Irvine, A. D., and Weidinger, S. (2020). Atopic dermatitis. Lancet 396, 345-360. doi: 10.1016/S0140-6736(20)31286-1

Leong, C., Schmid, B., Toi, M. J., Wang, J., Irudayaswamy, A. S., Goh, J. P. Z., et al. (2019). Geographical and Ethnic Differences Influence Culturable Commensal Yeast Diversity on Healthy Skin. Front. Microbiol. 10, 1891. doi: 10.3389/ fmicb.2019.01891

Leyden, J. J., Marples, R. R., and Kligman, A. M. (1974). Staphylococcus aureus in the lesions of atopic dermatitis. Br. J. Dermatol. 90, 525-530. doi: 10.1111/ j.1365-2133.1974.tb06447.x

Leyden, J. J., Mcginley, K. J., and Kligman, A. M. (1976). Role of microorganisms in dandruff. Arch. Dermatol. 112, 333-338. doi: 10.1001/archderm. 1976.01630270013003

Li, H., Goh, B. N., Teh, W. K., Jiang, Z., Goh, J. P. Z., Goh, A., et al. (2018). Skin Commensal Malassezia globosa Secreted Protease Attenuates Staphylococcus aureus Biofilm Formation. J. Invest. Dermatol. 138, 1137-1145. doi: 10.1016/ j.jid.2017.11.034

Li, B., Huang, L., Lv, P., Li, X., Liu, G., Chen, Y., et al. (2020). The role of Th17 cells in psoriasis. Immunol. Res. 68, 296-309. doi: 10.1007/s12026-020-09149-1

Limon, J. J., Skalski, J. H., and Underhill, D. M. (2017). Commensal Fungi in Health and Disease. Cell Host. Microbe 22, 156-165. doi: 10.1016/ j.chom.2017.07.002

Lunjani, N., Satitsuksanoa, P., Lukasik, Z., Sokolowska, M., Eiwegger, T., and O'mahony, L. (2018). Recent developments and highlights in mechanisms of allergic diseases: Microbiome. Allergy 73, 2314-2327. doi: 10.1111/all.13634

Malassez, L. (1874). Note sur la champignon de la pilade. Arch. Physiol. Norm. Pathol. 1, 203-212.

Mancini, A. J., Lawley, L. P., and Uzel, G. (2008). X-linked ectodermal dysplasia with immunodeficiency caused by NEMO mutation: early recognition and diagnosis. Arch. Dermatol. 144, 342-346. doi: 10.1001/archderm.144.3.342

Mayser, P. (2015). Medium chain fatty acid ethyl esters - activation of antimicrobial effects by Malassezia enzymes. Mycoses 58, 215-219. doi: $10.1111 /$ myc. 12300

Mcginley, K. J., Leyden, J. J., Marples, R. R., and Kligman, A. M. (1975). Quantitative microbiology of the scalp in non-dandruff, dandruff, and seborrheic dermatitis. J. Invest. Dermatol. 64, 401-405. doi: 10.1111/15231747.ep12512335

Mcgirt, L. Y., and Beck, L. A. (2006). Innate immune defects in atopic dermatitis. J. Allergy Clin. Immunol. 118, 202-208. doi: 10.1016/j.jaci.2006.04.033

Metze, D., Kersten, A., Jurecka, W., and Gebhart, W. (1991). Immunoglobulins coat microorganisms of skin surface: a comparative immunohistochemical and ultrastructural study of cutaneous and oral microbial symbionts. J. Invest. Dermatol. 96, 439-445. doi: 10.1111/1523-1747.ep12469908

Michalski, C., Kan, B., and Lavoie, P. M. (2017). Antifungal Immunological Defenses in Newborns. Front. Immunol. 8, 281. doi: 10.3389/fimmu.2017. 00281

Mittermann, I., Wikberg, G., Johansson, C., Lupinek, C., Lundeberg, L., Crameri, R., et al. (2016). IgE Sensitization Profiles Differ between Adult Patients with Severe and Moderate Atopic Dermatitis. PloS One 11, e0156077. doi: 10.1371/journal.pone.0156077

Nagata, R., Nagano, H., Ogishima, D., Nakamura, Y., Hiruma, M., and Sugita, T. (2012). Transmission of the major skin microbiota, Malassezia, from mother to neonate. Pediatr. Int. 54, 350-355. doi: 10.1111/j.1442-200X. 2012.03563.x

Naik, S., Bouladoux, N., Linehan, J. L., Han, S. J., Harrison, O. J., Wilhelm, C., et al. (2015). Commensal-dendritic-cell interaction specifies a unique protective skin immune signature. Nature 520, 104-108. doi: 10.1038/nature14052

Nakabayashi, A., Sei, Y., and Guillot, J. (2000). Identification of Malassezia species isolated from patients with seborrhoeic dermatitis, atopic dermatitis, pityriasis versicolor and normal subjects. Med. Mycol. 38, 337-341. doi: 10.1080/ mmy.38.5.337.341

Nakatsuji, T., Chen, T. H., Narala, S., Chun, K. A., Two, A. M., Yun, T., et al. (2017). Antimicrobials from human skin commensal bacteria protect against Staphylococcus aureus and are deficient in atopic dermatitis. Sci. Transl. Med. 9, 1-22. doi: 10.1126/scitranslmed.aah4680

Nehme, N. T., Schmid, J. P., Debeurme, F., Andre-Schmutz, I., Lim, A., Nitschke, P., et al. (2012). MST1 mutations in autosomal recessive primary immunodeficiency characterized by defective naive T-cell survival. Blood 119, 3458-3468. doi: 10.1182/blood-2011-09-378364

Ng, P. C. (1994). Systemic fungal infections in neonates. Arch. Dis. Child Fetal Neonatal. Ed. 71, F130-F135. doi: 10.1136/fn.71.2.F130

Nikkels, A. F., and Pierard, G. E. (2003). Framing the future of antifungals in atopic dermatitis. Dermatology 206, 398-400. doi: 10.1159/000069968

Nowicka, D., and Nawrot, U. (2019). Contribution of Malassezia spp. to the development of atopic dermatitis. Mycoses 62, 588-596. doi: 10.1111/ myc. 12913

Nutten, S. (2015). Atopic dermatitis: global epidemiology and risk factors. Ann. Nutr. Metab. 66 Suppl 1, 8-16. doi: 10.1159/000370220

Oh, K. J., Lee, S. E., Jung, H., Kim, G., Romero, R., and Yoon, B. H. (2010). Detection of ureaplasmas by the polymerase chain reaction in the amniotic fluid of patients with cervical insufficiency. J. Perinat. Med. 38, 261-268. doi: 10.1515/jpm.2010.040

Oh, J., Byrd, A. L., Deming, C., Conlan, S., Program, N. C. S., Kong, H. H., et al. (2014). Biogeography and individuality shape function in the human skin metagenome. Nature 514, 59-64. doi: 10.1038/nature13786

Oh, J., Byrd, A. L., Park, M., Program, N. C. S., Kong, H. H., and Segre, J. A. (2016). Temporal Stability of the Human Skin Microbiome. Cell 165, 854-866. doi: 10.1016/j.cell.2016.04.008

Page, C. O.Jr., and Remington, J. S. (1967). Immunologic studies in normal human sweat. J. Lab. Clin. Med. 69, 634-650.

Palmer, C. N., Irvine, A. D., Terron-Kwiatkowski, A., Zhao, Y., Liao, H., Lee, S. P., et al. (2006). Common loss-of-function variants of the epidermal barrier protein filaggrin are a major predisposing factor for atopic dermatitis. Nat. Genet. 38, 441-446. doi: 10.1038/ng1767

Patron, R. L. (2016). A 34-Year-Old Man With Cough, Lung Nodules, Fever, and Eosinophilia. Clin. Infect. Dis. 63, 1525-1526. doi: 10.1093/cid/ciw600

Pedrosa, A. F., Lisboa, C., and Rodrigues, A. G. (2018). Malassezia infections with systemic involvement: Figures and facts. J. Dermatol. 45, 1278-1282. doi: 10.1111/1346-8138.14653

Pelzer, E., Gomez-Arango, L. F., Barrett, H. L., and Nitert, M. D. (2017). Review: Maternal health and the placental microbiome. Placenta 54, 30-37. doi: 10.1016/j.placenta.2016.12.003

Perera, G. K., Di Meglio, P., and Nestle, F. O. (2012). Psoriasis. Annu. Rev. Pathol. 7, 385-422. doi: 10.1146/annurev-pathol-011811-132448

Philbin, V. J., and Levy, O. (2009). Developmental biology of the innate immune response: implications for neonatal and infant vaccine development. Pediatr. Res. 65, 98R-105R. doi: 10.1203/PDR.0b013e31819f195d

Pickens, W. L., Warner, R. R., Boissy, Y. L., Boissy, R. E., and Hoath, S. B. (2000). Characterization of vernix caseosa: water content, morphology, and elemental analysis. J. Invest. Dermatol. 115, 875-881. doi: 10.1046/j.15231747.2000.00134.x

Pilgram, G. S., Vissers, D. C., Van Der Meulen, H., Pavel, S., Lavrijsen, S. P., Bouwstra, J. A., et al. (2001). Aberrant lipid organization in stratum corneum of patients with atopic dermatitis and lamellar ichthyosis. J. Invest. Dermatol. 117, 710-717. doi: 10.1046/j.0022-202x.2001.01455.x

Poh, S. E., Goh, J. P. Z., Fan, C., Chua, W., Gan, S. Q., Lim, P. L. K., et al. (2020). Identification of Malassezia furfur Secreted Aspartyl Protease 1 (MfSAP1) and Its Role in Extracellular Matrix Degradation. Front. Cell Infect. Microbiol. 10, 148. doi: $10.3389 /$ fcimb. 2020.00148

Priestley, G. C., and Savin, J. A. (1976). The microbiology of dandruff. Br. J. Dermatol. 94, 469-471. doi: 10.1111/j.1365-2133.1976.tb06128.x

Prohic, A., Jovovic Sadikovic, T., Krupalija-Fazlic, M., and KuskunovicVlahovljak, S. (2016). Malassezia species in healthy skin and in dermatological conditions. Int. J. Dermatol. 55, 494-504. doi: 10.1111/ ijd.13116

Quaresma, J. A. S. (2019). Organization of the Skin Immune System and Compartmentalized Immune Responses in Infectious Diseases. Clin. Microbiol. Rev. 32, 1-35. doi: 10.1128/CMR.00034-18

Ramasamy, S., Barnard, E., Dawson, T. L.Jr., and Li, H. (2019). The role of the skin microbiota in acne pathophysiology. Br. J. Dermatol. 181, 691-699. doi: 10.1111/bjd. 18230

Rerknimitr, P., Otsuka, A., Nakashima, C., and Kabashima, K. (2017). The etiopathogenesis of atopic dermatitis: barrier disruption, immunological derangement, and pruritus. Inflammation Regener. 37, 14. doi: 10.1186/ s41232-017-0044-7 
Rhoda, W. B. (1939). The Cultural Characteristics of Pityrosporum Ovale-A Lipophylic Fungus. J. Invest. Dermatol. 2, 187-203. doi: 10.1038/jid.1939.17

Ro, B. I., and Dawson, T. L. (2005). The role of sebaceous gland activity and scalp microfloral metabolism in the etiology of seborrheic dermatitis and dandruff. $J$. Invest. Dermatol. Symp. Proc. 10, 194-197. doi: 10.1111/j.10870024.2005.10104.x

Rosenberg, E. W., and Belew, P. W. (1982). Improvement of psoriasis of the scalp with ketoconazole. Arch. Dermatol. 118, 370-371. doi: 10.1001/ archderm.1982.01650180004002

Saadatzadeh, M. R., Ashbee, H. R., Holland, K. T., and Ingham, E. (2001). Production of the mycelial phase of Malassezia in vitro. Med. Mycol. 39, 487-493. doi: 10.1080/mmy.39.6.487.493

Sabouraud, R. (1897). La seborrhee grasse et Ia pelade. Ann. Inst. Pasteur 11, 134.

Sandilands, A., Sutherland, C., Irvine, A. D., and Mclean, W. H. (2009). Filaggrin in the frontline: role in skin barrier function and disease. J. Cell Sci. 122, 12851294. doi: $10.1242 /$ jcs. 033969

Sandstrom Falk, M. H., Tengvall Linder, M., Johansson, C., Bartosik, J., Back, O., Sarnhult, T., et al. (2005). The prevalence of Malassezia yeasts in patients with atopic dermatitis, seborrhoeic dermatitis and healthy controls. Acta Derm. Venereol. 85, 17-23. doi: 10.1080/00015550410022276

Sankaranarayanan, S. R., Ianiri, G., Coelho, M. A., Reza, M. H., Thimmappa, B. C., Ganguly, P., et al. (2020). Loss of centromere function drives karyotype evolution in closely related Malassezia species. Elife 9, 1-33. doi: 10.7554/ eLife.53944

Sanmiguel, A., and Grice, E. A. (2015). Interactions between host factors and the skin microbiome. Cell Mol. Life Sci. 72, 1499-1515. doi: 10.1007/s00018-014-1812-z

Saunders, C. W., Scheynius, A., and Heitman, J. (2012). Malassezia fungi are specialized to live on skin and associated with dandruff, eczema, and other skin diseases. PloS Pathog. 8, e1002701. doi: 10.1371/journal.ppat.1002701

Saunte, D. M. L., Gaitanis, G., and Hay, R. J. (2020). Malassezia-Associated Skin Diseases, the Use of Diagnostics and Treatment. Front. Cell Infect. Microbiol. 10, 112. doi: $10.3389 /$ fcimb.2020.00112

Scharschmidt, T. C., Vasquez, K. S., Truong, H. A., Gearty, S. V., Pauli, M. L., Nosbaum, A., et al. (2015). A Wave of Regulatory T Cells into Neonatal Skin Mediates Tolerance to Commensal Microbes. Immunity 43, 1011-1021. doi: 10.1016/j.immuni.2015.10.016

Scheynius, A., Johansson, C., Buentke, E., Zargari, A., and Linder, M. T. (2002). Atopic eczema/dermatitis syndrome and Malassezia. Int. Arch. Allergy Immunol. 127, 161-169. doi: 10.1159/000053860

Schommer, N. N., and Gallo, R. L. (2013). Structure and function of the human skin microbiome. Trends Microbiol. 21, 660-668. doi: 10.1016/ j.tim.2013.10.001

Selander, C., Zargari, A., Mollby, R., Rasool, O., and Scheynius, A. (2006). Higher $\mathrm{pH}$ level, corresponding to that on the skin of patients with atopic eczema, stimulates the release of Malassezia sympodialis allergens. Allergy 61, 10021008. doi: 10.1111/j.1398-9995.2006.01108.x

Shek, Y. H., Tucker, M. C., Viciana, A. L., Manz, H. J., and Connor, D. H. (1989). Malassezia furfur-disseminated infection in premature infants. Am. J. Clin. Pathol. 92, 595-603. doi: 10.1093/ajcp/92.5.595

Silva, V., Fischman, O., and De Camargo, Z. P. (1997). Humoral immune response to Malassezia furfur in patients with pityriasis versicolor and seborrheic dermatitis. Mycopathologia 139, 79-85. doi: 10.1023/A:1006811704850

Simmons, R. B., and Gueho, E. (1990). A new species of Malassezia. Mycological Res. 94, 1146-1149. doi: 10.1016/S0953-7562(09)81349-X

Sohn, A. H., Garrett, D. O., Sinkowitz-Cochran, R. L., Grohskopf, L. A., Levine, G. L., Stover, B. H., et al. (2001). Prevalence of nosocomial infections in neonatal intensive care unit patients: Results from the first national point-prevalence survey. J. Pediatr. 139, 821-827. doi: 10.1067/mpd.2001.119442

Sparber, F., De Gregorio, C., Steckholzer, S., Ferreira, F. M., Dolowschiak, T., Ruchti, F., et al. (2019). The Skin Commensal Yeast Malassezia Triggers a Type 17 Response that Coordinates Anti-fungal Immunity and Exacerbates Skin Inflammation. Cell Host. Microbe 25389-403, e386. doi: 10.1016/ j.chom.2019.02.002

Sparber, F., and Leibundgut-Landmann, S. (2017). Host Responses to Malassezia spp. in the Mammalian Skin. Front. Immunol. 8, 1614. doi: 10.3389/ fimmu.2017.01614

Speer, M. E., Taber, L. H., Yow, M. D., Rudolph, A. J., Urteaga, J., and Waller, S. (1976). Fulminant neonatal sepsis and necrotizing enterocolitis associated with a "nonenteropathogenic" strain of Escherichia coli. J. Pediatr. 89, 91-95. doi: 10.1016/S0022-3476(76)80939-0

Sperling, R. S., Newton, E., and Gibbs, R. S. (1988). Intraamniotic infection in low-birth-weight infants. J. Infect. Dis. 157, 113-117. doi: 10.1093/infdis/ 157.1.113

Squiquera, L., Galimberti, R., Morelli, L., Plotkin, L., Milicich, R., Kowalckzuk, A., et al. (1994). Antibodies to proteins from Pityrosporum ovale in the sera from patients with psoriasis. Clin. Exp. Dermatol. 19, 289-293. doi: 10.1111/j.13652230.1994.tb01197.x

Stehlikova, Z., Kostovcik, M., Kostovcikova, K., Kverka, M., Juzlova, K., Rob, F., et al. (2019). Dysbiosis of Skin Microbiota in Psoriatic Patients: Co-occurrence of Fungal and Bacterial Communities. Front. Microbiol. 10, 438. doi: 10.3389/ fmicb.2019.00438

Sugita, T., Suto, H., Unno, T., Tsuboi, R., Ogawa, H., Shinoda, T., et al. (2001). Molecular analysis of Malassezia microflora on the skin of atopic dermatitis patients and healthy subjects. J. Clin. Microbiol. 39, 3486-3490. doi: 10.1128/ JCM.39.10.3486-3490.2001

Sugita, T., Takashima, M., Shinoda, T., Suto, H., Unno, T., Tsuboi, R., et al. (2002). New yeast species, Malassezia dermatis, isolated from patients with atopic dermatitis. J. Clin. Microbiol. 40, 1363-1367. doi: 10.1128/JCM.40.4.13631367.2002

Sugita, T., Takashima, M., Kodama, M., Tsuboi, R., and Nishikawa, A. (2003). Description of a new yeast species, Malassezia japonica, and its detection in patients with atopic dermatitis and healthy subjects. J. Clin. Microbiol. 41, 4695-4699. doi: 10.1128/JCM.41.10.4695-4699.2003

Sugita, T., Tajima, M., Takashima, M., Amaya, M., Saito, M., Tsuboi, R., et al. (2004). A new yeast, Malassezia yamatoensis, isolated from a patient with seborrheic dermatitis, and its distribution in patients and healthy subjects. Microbiol. Immunol. 48, 579-583. doi: 10.1111/j.1348-0421.2004.tb03554.x

Szabo, K., Erdei, L., Bolla, B. S., Tax, G., Biro, T., and Kemeny, L. (2017). Factors shaping the composition of the cutaneous microbiota. Br. J. Dermatol. 176 , 344-351. doi: 10.1111/bjd.14967

Tateno, H., Ohnishi, K., Yabe, R., Hayatsu, N., Sato, T., Takeya, M., et al. (2010). Dual specificity of Langerin to sulfated and mannosylated glycans via a single C-type carbohydrate recognition domain. J. Biol. Chem. 285, 6390-6400. doi: 10.1074/jbc.M109.041863

Theelen, B., Cafarchia, C., Gaitanis, G., Bassukas, I. D., Boekhout, T., and Dawson, T. L.Jr. (2018). Malassezia ecology, pathophysiology, and treatment. Med. Mycol. 56, S10-S25. doi: 10.1093/mmy/myx134

Theelen, B., Cafarchia, C., Gaitanis, G., Bassukas, I. D., Boekhout, T., and Dawson, T. L. (2019). Corrigendum: Malassezia ecology, pathophysiology, and treatment. Med. Mycol. 57, e2. doi: 10.1093/mmy/myy046

Tipton, L., Muller, C. L., Kurtz, Z. D., Huang, L., Kleerup, E., Morris, A., et al. (2018). Fungi stabilize connectivity in the lung and skin microbial ecosystems. Microbiome 6, 12. doi: 10.1186/s40168-017-0393-0

Tollin, M., Bergsson, G., Kai-Larsen, Y., Lengqvist, J., Sjovall, J., Griffiths, W., et al. (2005). Vernix caseosa as a multi-component defence system based on polypeptides, lipids and their interactions. Cell Mol. Life Sci. 62, 2390-2399. doi: 10.1007/s00018-005-5260-7

Two, A. M., Nakatsuji, T., Kotol, P. F., Arvanitidou, E., Du-Thumm, L., Hata, T. R., et al. (2016). The Cutaneous Microbiome and Aspects of Skin Antimicrobial Defense System Resist Acute Treatment with Topical Skin Cleansers. J. Invest. Dermatol. 136, 1950-1954. doi: 10.1016/j.jid.2016.06.612

Underhill, D. M., and Pearlman, E. (2015). Immune Interactions with Pathogenic and Commensal Fungi: A Two-Way Street. Immunity 43, 845-858. doi: 10.1016/j.immuni.2015.10.023

Valli, J. L., Williamson, A., Sharif, S., Rice, J., and Shewen, P. E. (2010). In vitro cytokine responses of peripheral blood mononuclear cells from healthy dogs to distemper virus, Malassezia and Toxocara. Vet. Immunol. Immunopathol. 134, 218-229. doi: 10.1016/j.vetimm.2009.09.023

Vanderwyk, R. (1964). The relationship between dandruff and the microbial flora of the human scalp. J. Soc. Cosmet. Chem. 15, 761-768.

Vanderwyk, R. (1967). A comparison of the bacterial and yeast flora of the human scalp and their effect upon dandruff production. J. Soc. Cosmet. Chem. 639, 629-639.

Vilhelmsson, M., Johansson, C., Jacobsson-Ekman, G., Crameri, R., Zargari, A., and Scheynius, A. (2007). The Malassezia sympodialis allergen Mala s 11 induces human dendritic cell maturation, in contrast to its human homologue 
manganese superoxide dismutase. Int. Arch. Allergy Immunol. 143, 155-162. doi: $10.1159 / 000099082$

Vlachos, C., Schulte, B. M., Magiatis, P., Adema, G. J., and Gaitanis, G. (2012). Malassezia-derived indoles activate the aryl hydrocarbon receptor and inhibit Toll-like receptor-induced maturation in monocyte-derived dendritic cells. $\mathrm{Br}$. J. Dermatol. 167, 496-505. doi: 10.1111/j.1365-2133.2012.11014.x

Wananukul, S., Chindamporn, A., Yumyourn, P., Payungporn, S., Samathi, C., and Poovorawan, Y. (2005). Malassezia furfur in infantile seborrheic dermatitis. Asian Pac. J. Allergy Immunol. 23, 101-105.

Ward, T. L., Dominguez-Bello, M. G., Heisel, T., Al-Ghalith, G., Knights, D., and Gale, C. A. (2018). Development of the Human Mycobiome over the First Month of Life and across Body Sites. mSystems 3, 1-12. doi: 10.1128/ mSystems.00140-17

Warner, R. R., Schwartz, J. R., Boissy, Y., and Dawson, T. L.Jr. (2001). Dandruff has an altered stratum corneum ultrastructure that is improved with zinc pyrithione shampoo. J. Am. Acad. Dermatol. 45, 897-903. doi: 10.1067/mjd. 2001.117849

Weidinger, S., Beck, L. A., Bieber, T., Kabashima, K., and Irvine, A. D. (2018). Atopic dermatitis. Nat. Rev. Dis. Primers 4, 1. doi: 10.1038/s41572-018-0001-z

White, T. C., Findley, K., Dawson, T. L.Jr., Scheynius, A., Boekhout, T., Cuomo, C. A., et al. (2014). Fungi on the skin: dermatophytes and Malassezia. Cold Spring Harb. Perspect. Med. 4, 1-16. doi: 10.1101/cshperspect.a019802

Wu, G., Zhao, H., Li, C., Rajapakse, M. P., Wong, W. C., Xu, J., et al. (2015). Genus-Wide Comparative Genomics of Malassezia Delineates Its Phylogeny, Physiology, and Niche Adaptation on Human Skin. PloS Genet. 11, e1005614. doi: 10.1371/journal.pgen.1005614

Xu, J., Saunders, C. W., Hu, P., Grant, R. A., Boekhout, T., Kuramae, E. E., et al. (2007). Dandruff-associated Malassezia genomes reveal convergent and divergent virulence traits shared with plant and human fungal pathogens. Proc. Natl. Acad. Sci. U.S.A. 104, 18730-18735. doi: 10.1073/pnas.0706756104

Yang, G., Seok, J. K., Kang, H. C., Cho, Y. Y., Lee, H. S., and Lee, J. Y. (2020). Skin Barrier Abnormalities and Immune Dysfunction in Atopic Dermatitis. Int. J. Mol. Sci. 21, 1-14. doi: 10.3390/ijms21082867.

Zargari, A., Eshaghi, H., Back, O., Johansson, S., and Scheynius, A. (2001). Serum IgE reactivity to Malassezia furfur extract and recombinant $M$. furfur allergens in patients with atopic dermatitis. Acta Derm. Venereol. 81, 418-422. doi: $10.1080 / 000155501317208363$

Zhang, Y., Kastman, E. K., Guasto, J. S., and Wolfe, B. E. (2018). Fungal networks shape dynamics of bacterial dispersal and community assembly in cheese rind microbiomes. Nat. Commun. 9, 336. doi: 10.1038/s41467-017-02522-z

Zhang, L. J., and Gallo, R. L. (2016). Antimicrobial peptides. Curr. Biol. 26, R14R19. doi: 10.1016/j.cub.2015.11.017

Zuniga, R., and Nguyen, T. (2013). Skin conditions: common skin rashes in infants. FP Essent. 407, 31-41.

Conflict of Interest: The authors declare that the research was conducted in the absence of any commercial or financial relationships that could be construed as a potential conflict of interest.

Copyright (c) 2021 Vijaya Chandra, Srinivas, Dawson and Common. This is an openaccess article distributed under the terms of the Creative Commons Attribution License (CC BY). The use, distribution or reproduction in other forums is permitted, provided the original author(s) and the copyright owner(s) are credited and that the original publication in this journal is cited, in accordance with accepted academic practice. No use, distribution or reproduction is permitted which does not comply with these terms. 